\title{
Gold nanoparticle/nickel oxide/poly(pyrrole- $N$-propionic acid) hybrid multilayer film: Electrochemical study and its application in biosensing
}

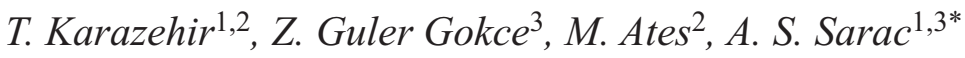 \\ ${ }^{1}$ Department of Chemistry, Polymer Science \& Technology, Istanbul Technical University, Maslak, 34469 Istanbul, \\ Turkey \\ ${ }^{2}$ Department of Chemistry, Faculty of Arts and Sciences, Namik Kemal University, Degirmenalti Campus, 59030 \\ Tekirdag, Turkey \\ ${ }^{3}$ Nano-Science \&Nano-Engineering, Istanbul Technical University, Maslak, 34469 Istanbul, Turkey
}

Received 24 October 2016; accepted in revised form 19 January 2017

\begin{abstract}
The present study describes the fabrication of Indium Tin Oxide /gold nanoparticles/nickel oxide/poly(Pyrrole$\mathrm{N}$-propionic acid) (ITO/GNPs/NiO/poly(PPA)) multilayered film, and its modification with Tyrosinase (Ty). The ITO/GNPs/ $\mathrm{NiO} /$ poly(PPA) electrode was fabricated by sequential electrochemical assembly onto ITO substrate which electrochemical deposition provides a facile, inexpensive technique for synthesis of multilayered film within the adherent morphology with controllable film thickness. Cyclic voltammetry (CV), Fourier transform infrared spectroscopy-attenuated total reflectance (FTIR-ATR), scanning electron microcopy (SEM), and atomic force microcopy (AFM) were used to characterize the film assembly processes. The properties of a semiconductor/electrolyte interface were investigated based on the Mott-Schottky $(\mathrm{M}-\mathrm{S})$ approach for the modified electrodes, with the flat band potential $\left(E_{\mathrm{FB}}\right)$ according to the potential intercept and the carrier density $\left(N_{\mathrm{D}}\right)$ according to the linear slopes. The $N_{\mathrm{D}}$ and $E_{\mathrm{FB}}$ of ITO/GNPs/NiO/poly(PPA) were obtained as $2.48 \cdot 10^{21} \mathrm{~cm}^{-3}$ and $0.26 \mathrm{~V}$, respectively. Tyrosinase was immobilized using carbodiimide coupling reaction. The bioelectrode was characterized by FTIR-ATR, SEM, AFM, electrochemical impedance spectroscopy (EIS). A Randles equivalent circuit was introduced for modeling the performance of impedimetric biosensing for the detection of the dopamine (DP) and the interface of bioelectrode/electrolyte. The EIS of the ITO/GNPs/NiO/poly(PPA)-Ty exhibited significant changes in the charge transfer resistance $\left(R_{\mathrm{CT}}\right)$ value toward the detection of dopamine over a linear range of $80 \mu \mathrm{M}$ to $0.2 \mathrm{mM}$ with a limit of detection (LOD) of $5.46 \mu \mathrm{M}$.
\end{abstract}

Keywords: polymer composites, poly(pyrrole-N-propionic acid), Mott-Schottky, tyrosinase, dopamine

\section{Introduction}

Conducting polymers (CPs) have been widely used in advanced technologies. They are utilized for technological devices such as biosensors [1], photovoltaic cells [2], light-emitting diodes [3], and supercapacitors [4]. Selection of a suitable solid matrix that facilitates immobilization of the desired biomolecules is important for biosensor construction. In this context, $\mathrm{CPs}$ are one of the best candidates for immobilizing biomolecules. Hence, they are preferred as an immobilization matrix that provides significant advantages due to their good conductivity and mechanical properties, and good adhesion to the electrode surface [5-7]. Recently, the pyrrole derivative, pyrrole1-propionic acid (PPA), has emerged as a novel polymer matrix (poly(pyrrole- $N$-propionic acid)) for biosensor applications [8-10]. PPA has been applied for this purpose because its carboxylic acid group

${ }^{*}$ Corresponding author, e-mail: sarac@itu.edu.tr (C) BME-PT 
provides immobilization for covalent linking of enzymes.

In recent years, advances in bioelectrochemistry have centered on investigations of nanomaterials. Among a variety of nanomaterials, gold nanoparticles (GNPs), which can be easily obtained through electrochemical techniques, are one of the most attractive due to their interesting properties arising from larger active surface area and improved electron transport in biosensor studies $[11,12]$. Metal oxide nanoparticles as a nanomaterial have drawn great attention due to their optical, magnetic, and electronic properties [13]. Among them, nickel oxide $(\mathrm{NiO})$ is a promising material for the development of biosensors due to its high chemical stability, high electron transfer properties, high electrocatalytic properties, nontoxicity, and biocompatibility [14]. It is reported that nickel oxide nanoparticles modified electrodes exhibited high electrocatalytic activity toward different biological materials $[15,16]$. GNPs and NiO nanoparticles have been reported in literature to improve the electrode's surface area as well as its sensitivity toward analyte [17]. It is believed that nanomaterials together with CPs as a transducer will be widely used in the construction of biosensor devices when the physicochemical properties of produced composite are modified for more and more particular needs [18]. In this context, to improve the performance of electrochemical biosensors, the above mentioned nanomaterials have been composed of conductive polymer in general, such as polyaniline, polypyrrole, and polythiophene [19-23]. It is expected that these composites offer a synergic effect to overcome the limitation (low electron mobility) of conducting polymer-based technological applications [24]. Therefore, conducting polymers have been of great interest with both the metal and the metal oxide nano-structures due to their ability to generate additional electro-catalytic sites as well as the probable electronic interactions between these nanostructures and groups in the polymer [25].

Multi-layered structures have been of interest in recent years due to improved physical properties such as high hardness, fracture toughness, chemical inertness and resistance to corrosion $[26,27]$. In these multilayer structures, multiple functions can be integrated into a single system with their different electrochemical properties [28]. To obtain multilayer configurations, various alternative approaches, such as layerby-layer [29], bio-interactions [30], electrodeposition
[31], and covalent binding [32] have been reported. The electrodeposition technique is useful due to its rapidity, and simplicity. The properties of the resulting structures can be controlled by altering assembly conditions, which is an advantage for obtaining the desired properties [33].

Development of simple and reliable methods for the immobilization of enzymes is a crucial step in the fabrication of biosensors. The stability, reproducibility, and sensitivity as well as the lifetime of the biosensor depend on the strategy of immobilization of the enzymes. Many methods such as adsorption of enzyme on to the solid surface [34], incorporation into conducting polymers [35], and covalent immobilization [36], or crosslinking to a matrix [37] have been used as valuable techniques for immobilization. Of all these immobilization methods, covalent coupling has an advantage in terms of leaking of enzyme during reuse, limited electron flow and storage stability [38].

The aim of this work was to construct an impedimetric dopamine biosensor based on tyrosinase which was covalently immobilized onto a novel multilayered film formed by electrodepositon of poly(pyrrole- $N$ propionic acid), nickel oxide, and gold nanoparticles (GNPs) onto ITO. The ITO/GNPs/NiO/poly(PPA) electrode assembly was performed by sequential electrochemical deposition. The multilayer films assembling and characterization were studied by CV, FTIRATR, SEM, AFM, and Mott-Schottky analysis. To prepare enzyme electrodes, the covalent immobilization of tyrosinase Ty was achieved by reacting amino $\left(-\mathrm{NH}_{2}\right)$ groups of Ty with a carboxyl $(-\mathrm{COOH})$ group containing poly(PPA) by using ethyl(dimethylaminopropyl) carbodiimide/N-hydroxy succinimide (EDC/ NHS) activation (Figure 1). The performance of the Ty based electrode (ITO/GNPs/NiO/poly(PPA)-Ty) was investigated using impedance spectroscopy technique for detection of dopamine. This multilayered configuration is suitable for an efficient enzyme-immobilization matrix, enhancing the sensitivity and selectivity of the biosensor.

\section{Experimental}

\subsection{Materials and apparatus}

Hydrogen tetrachloroaurate $(99.99 \%, 254169$, Sigma Aldrich, USA), pyrrole- $N$-propionic acid (97\%, 687545, Sigma Aldrich, USA), sodium perchlorate (99\% 381225, Sigma Aldrich, USA), acetonitrile (99.8\% 271004, Sigma Aldrich, USA), potassium hexacyanoferrate (III), (99\%, 393517, Sigma Aldrich, 

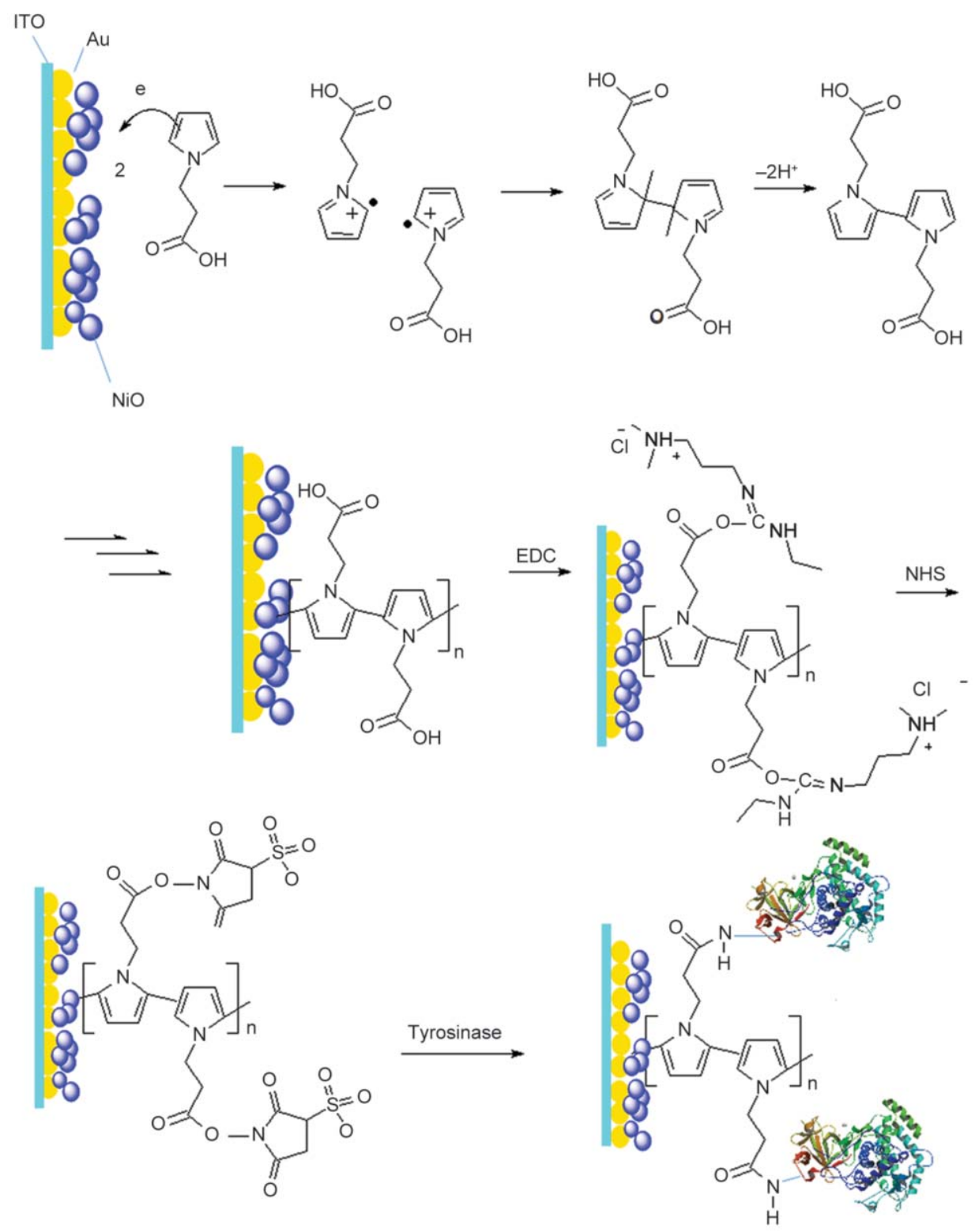

Figure 1. Schematic diagram of electrode fabrication process and tentative mechanism of polymerization of PPA

USA), potassium hexacyanoferrate(II) trihydrate, (99.5\% 60279, Sigma Aldrich, USA), sodium sulfate, (99\%, S6547, Sigma Aldrich, USA), tyrosinase from mushrooms (EC 1.14.18.1, T3824, Sigma Aldrich, USA), $N$-(3-Dimethylaminopropyl)- $N$ '-ethylcarbodiimidehydrochloride (99\%, 03449, Sigma Aldrich, USA), $N$-hydroxysuccinimide (98\% 130672, Sigma Aldrich, USA), Glucose (99.5\%, G8220, Sigma Aldrich, USA), and ascorbic acid (99\%, A5960, Sigma Aldrich, USA) were used as received. The phosphate buffer solution ( $\mathrm{pH}$ 7.0, 0.2 $\mathrm{M}$ and $\mathrm{pH}$ 7.4, 0.1 M) was freshly prepared using sodium phosphate dibasic anhydrous (98.5\%, 71642, Sigma Aldrich, USA), and sodium phosphate monobasic $(99 \%, 71505$, Sigma Aldrich, USA). An acetate buffer solution $(0.1 \mathrm{M}$ $\mathrm{pH}=4)$ (sodium acetate trihydrate $(99 \%, \mathrm{~S} 7670$,
Sigma Aldrich, USA), and acetic acid (71251, Sigma Aldrich, USA) was also freshly prepared. Nickel (II) nitrate hexahydrate, $(98.5 \%)$ was purchased from Carlo Erba Reagents. ITO-coated glass slides with surface resistivity values of $8-12 \Omega /$ sq (703192) were also obtained from Sigma Aldrich. Ultrapure water $\left(18.2 \mathrm{M} \Omega \cdot \mathrm{cm}^{-1}\right)$ produced by ElgaPurelab Option Q (USA) was used in all experiments.

A conventional three-electrode cell configuration was used for modified ITO substrates as a working electrode, platinum wire served as an auxiliary electrode, and $\mathrm{Ag}$ wire served as the reference electrode which was checked by ferrocene. CV was performed using Ivium vertex (software, Ivium soft and Faraday cage, BAS Cell Stand $\mathrm{C}_{3}$ ). SEM was performed with a Gemini Leo Supra 35 VP. AFM analysis was 
performed using a Nanosurf Easy Scan AFM with a scan tip of $10 \mu \mathrm{m}$. AFM images were obtained using a non-contact mode. EIS measurements were taken in PBS $(0.1 \mathrm{M} \quad \mathrm{pH} 7.4)$ containing $2.5 \mathrm{mM}$ $\left[\mathrm{Fe}(\mathrm{CN})_{6}^{3-/ 4}\right]$ redox probe to investigate electrodes/ electrolyte interface properties of Ty modified electrode with parstat 2263 (software; Powersuit, USA). The impedance spectra were analyzed using a ZSimpWin V3.22. IR spectra were recorded using FTIR reflectance spectroscopy (Perkin Elmer, Spectrum One B, with an ATR attachment Universal ATR-with a ZnSe crystal, C70951, USA). The Raman spectrum of $\mathrm{NiO}$ was taken using a DXR Raman spectrometer (Thermo Scientific, Massachusetts, USA) at $532 \mathrm{~nm}$. The Crystalline structure of $\mathrm{NiO}$ was analyzed by XRD (Shimadzu XRD-6000). The semiconducting properties of modified electrodes were determined by employing the M-S approach, using Ivium vertex equipment. The capacitance measurements were performed at a frequency of $5 \mathrm{kHz}$ with applied various biases at successive steps of $20 \mathrm{mV}$ (vs. Ag). Dissolved oxygen was removed by bubbling nitrogen gas for 10 minutes before M-S analysis.

\subsection{Electrochemical synthesis of ITO/GNPs/NiO/poly(PPA) electrode}

GNPs and NiO nanoparticles were synthesized according to literature $[39,40]$. Electrochemical deposition of GNPs and $\mathrm{NiO}$ were performed onto the ITO substrate under $\mathrm{N}_{2}$ saturated buffer solution due to eliminate contribution of reduction peak current of $\mathrm{O}_{2}$ during the cathodic scan. ITO was cut in rectangular pieces of $1 \times 2 \mathrm{~cm}$ and cleaned ultrasonically with diluted ammonia, ethanol, and distilled water for $5 \mathrm{~min}$, and then immersed in a solution of $1 \mathrm{mM} \mathrm{HAuCl}_{4}$ in a $0.2 \mathrm{M}$ phosphate buffer solution ( $\mathrm{PBS}, \mathrm{pH}=7.0$ ) to the deposited GNPs, where the potential range was from 0.1 to $-0.9 \mathrm{~V}$ for 20 cycles and the scan rate was $0.05 \mathrm{~V} / \mathrm{s}$. After the GNP-modified ITO was cleaned using distilled water, the $\mathrm{NiO}$ was deposited by scanning the potential of the GNP-modified ITO (ITO/ GNPs) between -1.2 and $0 \mathrm{~V}$ vs. Ag wire at a scan rate of $0.05 \mathrm{~V} / \mathrm{s}$ for 20 cycles in a $0.1 \mathrm{M}$ acetate buffer solution (0.1 M ABS, $\mathrm{pH} 4.0)$ containing $10 \mathrm{mM} \mathrm{Ni}\left(\mathrm{NO}_{3}\right)_{2}$. The modified electrode was once again rinsed with distilled water. The polymerization process was performed in $0.1 \mathrm{M} \mathrm{NaClO}_{4} / \mathrm{ACN}$ solutions containing initial monomer (PPA) concentrations of $10 \mathrm{mM}$ onto ITO/GNPs and ITO/GNPs/NiO in the potential range from 0 to $1.4 \mathrm{~V}$ at a scan rate of $0.05 \mathrm{~V} / \mathrm{s}$.

\subsection{Covalent immobilization of tyrosinase}

Ty was immobilized onto the poly(PPA) modified electrodes using the EDC/NHS activation procedure. The carboxyl $(-\mathrm{COOH})$ groups of poly(PPA) were activated by shaken gently for $2 \mathrm{~h}$ at room temperature with $5 \mathrm{~mL}$ of EDC/NHS solution (1:1 molar ratio, $10 \mathrm{mM}$ in $0.1 \mathrm{M}$ PBS buffer with $\mathrm{pH}$ 7.4). Activated electrodes were then washed twice with PBS buffer and treated with Ty solution with a concentration of $0.5 \mathrm{mg} / \mathrm{mL}$ for another $2 \mathrm{~h}$ at $+4^{\circ} \mathrm{C}$ and shaken gently. Finally, the electrodes were removed, washed twice with PBS buffer to remove the physically absorbed enzyme, and dried for characterization. The resulting Ty-immobilized electrodes were named as ITO/ GNPs/poly(PPA)-Ty and ITO/GNPs/NiO/poly(PPA)Ty. The enzyme modified electrodes were characterized using FTIR-ATR, SEM, AFM, and EIS measurements. Ty based electrodes were stored at $4{ }^{\circ} \mathrm{C}$ when not in use.

\section{Results and discussion}

\subsection{Fabrication of ITO/GNPs/NiO/poly(PPA) electrode}

The electrodeposition of GNPs, GNPs/NiO, GNPs/ poly(PPA) and GNPs/NiO/poly(PPA) are presented in Figure 2. The application of a low potential is important in $\mathrm{CV}$ to grow metallic nanoparticles onto substrates. Metallic nanoparticle deposition includes two basic processes: nucleation arising from the large overpotential required for nucleation onto ITO compared to the deposition of gold onto gold [41], and a particle growth step [42]. According to Figure 2a, the curve exhibited a characteristic nucleation loop in the first cycle [43]. The CV in the $5^{\text {th }}$ cycle exhibited two peaks: a reduction peak of $\mathrm{Au}^{3+}$ and an oxidation peak of $\mathrm{Au}$. The reduction peak potential of $\mathrm{Au}^{3+}$ occurred at $-0.48 \mathrm{~V}$ and the oxidation peak potential of $\mathrm{Au}$ at $-0.09 \mathrm{~V}$. The reduction peak current increased with an increase in the number of cycles due to the growth of the GNPs [44, 45].

We deposited NiO onto the GNP-modified ITO electrode by performing a cathodic potential scan $(-1.2$ to $0.0 \mathrm{~V})$ at an initial concentration of $10 \mathrm{mM} \mathrm{Ni}\left(\mathrm{NO}_{3}\right)_{2}$. $\mathrm{NiO}$ formation takes place via an intermediate step. Figure $2 \mathrm{~b}$ displays the $\mathrm{CV}$ of $\mathrm{NiO}$ onto the GNP modified ITO. The weak peak current at $-0.41 \mathrm{~V}$ 

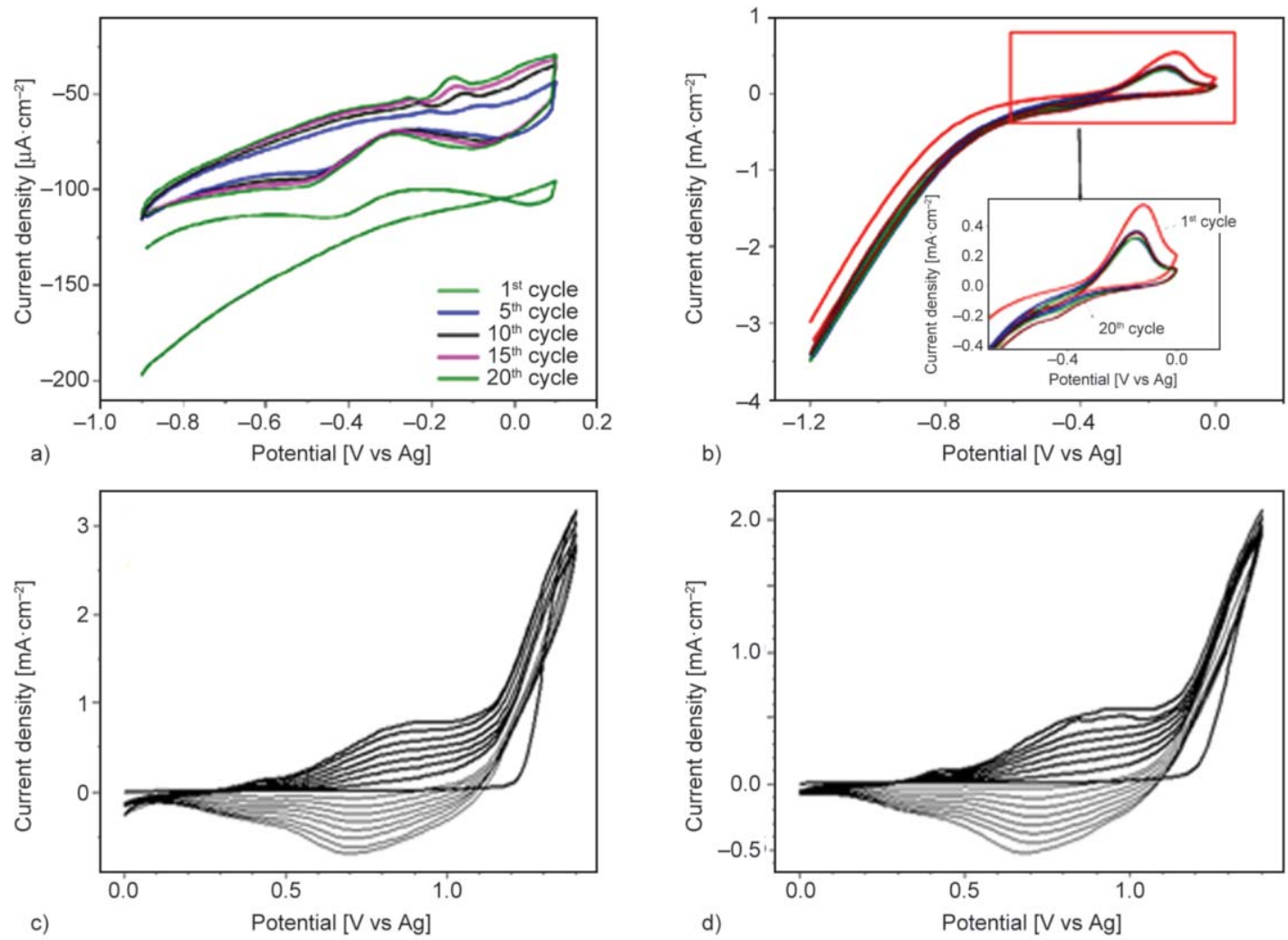

Figure 2. CV scans of a) electrodeposition of GNPs onto ITO electrode at a scan rate of $0.05 \mathrm{~V} / \mathrm{s}$ containing $1 \mathrm{mM}$ of $\mathrm{HAuCl}_{4}$ in $0.02 \mathrm{M}$ phosphate buffer solution ( $\mathrm{pH} 7.0$ ), 20 cycle, b) deposition of $\mathrm{NiO}$ onto ITO/GNPs in $0.1 \mathrm{M}$ ABS (pH 4.0) containing $10 \mathrm{mM} \mathrm{Ni}\left(\mathrm{NO}_{3}\right)_{2}$ at a scan rate of $0.05 \mathrm{~V} / \mathrm{s}, 20$ cycle, c) electrogrowth of poly(pyrrole- $N$-propionic acid) onto ITO/GNPs, d) electrogrowth of poly(pyrrole-N-propionic acid) onto ITO/GNPs/NiO; polymerization conditions: $[\mathrm{PPA}]_{0}=10 \mathrm{mM}$, potential range: $0-1.4 \mathrm{~V}$, scan rate: $50 \mathrm{mV} \cdot \mathrm{s}^{-1}$, in $0.1 \mathrm{M} \mathrm{NaClO} / \mathrm{can}, 8$ cycle

was due to reduction of $\mathrm{Ni}^{+2}$ [39]. A large cathodic current beyond the potential of $-0.5 \mathrm{~V}$ in the $\mathrm{CV}$ indicated the growth of $\mathrm{NiO}$ (Figure $2 \mathrm{~b}$ ) [46]. The anodic peak during the anodic scan, nearly at $-0.14 \mathrm{~V}$, corresponded to the dissolution of the formed metallic $\mathrm{Ni}$.

The CV for pyrrole- $N$-propionic acid (PPA) during the electrogrowth process on the ITO/GNPs and ITO/ GNPs/NiO is presented in Figures $2 \mathrm{c}$ and $2 \mathrm{~d}$, respectively. The current of the oxidative wave increased with increasing cycle number, indicating the formation of a poly(PPA) film onto the GNPs and GNPs/ $\mathrm{NiO}$ modified ITO electrodes (Figures 2c, 2d). Better polymerization was obtained in the ITO/GNPs/ poly(PPA) electrode due to the higher conductivity of GNPs. The oxidation and reduction potentials of the polymers shifted to slightly cathodic values in the following order: $E_{\mathrm{pa} 1}=0.42 \mathrm{~V}, E_{\mathrm{pa} 2}=0.86 \mathrm{~V}$, $E_{\mathrm{pc} 1}=0.30 \mathrm{~V}, E_{\mathrm{pc} 2}=0.69 \mathrm{~V}(\mathrm{ITO} / \mathrm{GNPs} /$ poly $(\mathrm{PPA}))$, $E_{\mathrm{pa} 1}=0.41 \mathrm{~V}, E_{\mathrm{pa} 2}=0.83 \mathrm{~V}, E_{\mathrm{pc} 1}=0.29 \mathrm{~V}$, and $E_{\mathrm{pc} 2}=0.68 \mathrm{~V}(\mathrm{ITO} / \mathrm{GNPs} / \mathrm{NiO} /$ poly $(\mathrm{PPA}))$ [47].

\subsection{Electrochemical characterization of ITO/GNPs/NiO/poly(PPA) electrode in redox couple of $\mathrm{Fe}(\mathrm{III}) / \mathrm{Fe}$ (II).}

The modified electrodes were characterized on basic electrochemical redox probe of potassium ferrocyanide-ferricyanide. The CV scans of the bare ITO, ITO/GNPs, ITO/GNPs/NiO, and ITO/poly(PPA) in a redox probe of $10 \mathrm{mM}\left[\mathrm{Fe}(\mathrm{CN})_{6}\right]^{3-/ 4-}$ containing $0.1 \mathrm{M} \mathrm{KCl}$ were recorded in the range of -0.2 to $+0.6 \mathrm{~V}$ and they are presented in Figure 3. ITO/GNPs/ poly(PPA) and ITO/GNPs/NiO/poly(PPA) are shown in the inset of Figure 3. A pair of well-defined peaks is observed for the both bare ITO electrode and the modified ITO. The $\Delta E_{\mathrm{p}}$ of the redox couple waves was $0.37 \mathrm{~V}$ for the bare ITO. An increase in the peak current $\left(I_{\mathrm{pAGNPS}} / I_{\mathrm{pABare} \text { ITO }}=1.33\right)$ and a decrease in $\Delta E_{\mathrm{p}}(0.35 \mathrm{~V})$ were observed upon attachment of the GNPs, indicating an increase in the source of electron transfer rate. This is attributed to the fact that the GNPs could enhance the electrodes' effective surface area and conductivity. Deposition of the $\mathrm{NiO}$ onto the 
ITO/GNP electrode resulted in the sluggish electron transfer of redox couple $\left(I_{\mathrm{pAGNP} / \mathrm{NiO}} / I_{\mathrm{pABare} \text { ITO }}=\right.$ 1.25 ) due to presence of $\mathrm{NiO}$, which has lower conductivity than that of GNPs (Figure 3). However, it showed an enhanced $\Delta E_{\mathrm{p}}$ which was $0.27 \mathrm{~V}$. This indicates that the surface was effectively improved by depositing NiO. The modification of poly(PPA) with the ITO/GNPs/NiO and ITO/GNPs electrodes resulted in a decrease in peak current, indicating the inhibited electron transfer between the poly(PPA) modified electrodes and redox probe $\left[\mathrm{Fe}(\mathrm{CN})_{6}\right]^{3-/ 4-}$ (inset in Figure 3). The $\Delta E_{\mathrm{p}}$ of ITO/GNPs/NiO/poly(PPA) was $0.14 \mathrm{~V}$ when compared to that for ITO/GNPs/ poly(PPA), which was $0.23 \mathrm{~V}$. These results indicated that the ITO/GNPs/NiO/poly(PPA) was more electroactive than ITO/GNPs/poly(PPA), and the surface

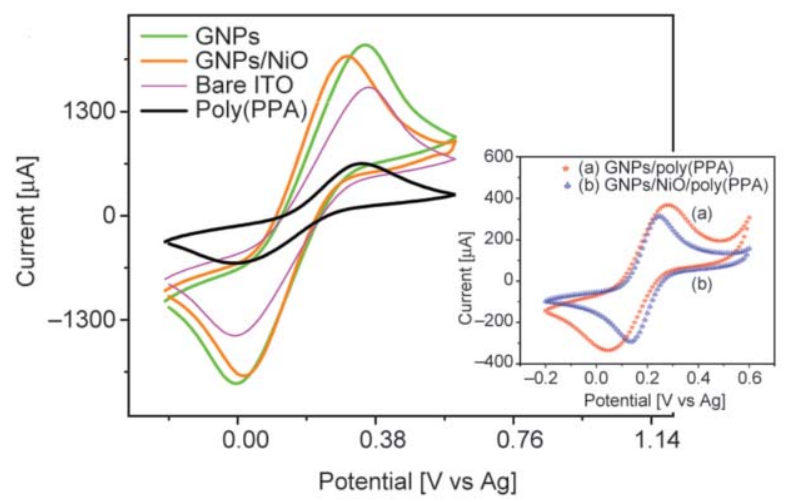

Figure 3. $\mathrm{CV}$ scans for bare ITO, ITO/GNPs, ITO/GNPs/NiO, and ITO/poly(PPA) in $10.0 \mathrm{mM}\left[\mathrm{Fe}(\mathrm{CN})_{6}^{3-/ 4}\right]$ redox probe containing $0.1 \mathrm{M} \mathrm{KCl}$. Inset shows ITO/ GNPs/poly(PPA) (a) and ITO/GNPs/NiO/poly (PPA) (b); potential range; -0.2 to $0.6 \mathrm{~V}$, Scan rate; $100 \mathrm{mV} \cdot \mathrm{s}^{-1}$

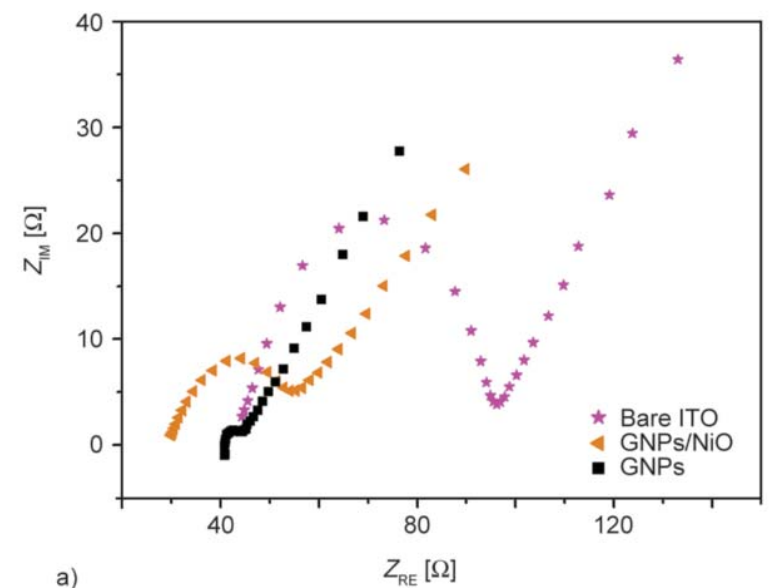

was effectively improved under the same process of electrochemical deposition because of the existence of $\mathrm{NiO}$

The stepwise assembly in the fabrication process was also investigated using EIS. Figure 4 show the EIS of different modified electrodes in $10 \mathrm{mM} \mathrm{Fe}(\mathrm{CN})_{6}^{3-/ 4}$ as a redox probe containing $0.1 \mathrm{M} \mathrm{KCl}$ in the frequency range $10^{5}-0.1 \mathrm{~Hz}$. Figure 4 shows a well-defined semicircle curve, indicating the charge transfer process was obtained for both bare and modified electrodes. The charge $R_{\mathrm{CT}}$ values were obtained using equivalent circuit model of $\mathrm{R}(\mathrm{Q}(\mathrm{RW}))$. The $R_{\mathrm{CT}}$ for bare ITO and ITO/GNPs were 50.51 and $8.09 \Omega$, respectively (Figure $4 \mathrm{a})$ ). The decrease in $R_{\mathrm{CT}}$ value in the presence of GNPs revealed that the electron transfer via redox couple was enhanced with the modification of GNPs. This result is ascribed to the conductivity of GNPs. After $\mathrm{NiO}$ was deposited onto the ITO/GNPs electrode, the value of $R_{\mathrm{CT}}$ increased from 8.09 to $29.04 \Omega$ due to low conductivity of $\mathrm{NiO}$ compared with the ITO/GNPs (Figure 4a). In the case of the ITO/poly(PPA) electrode (inset in Figure 4b), the $R_{\mathrm{CT}}$ was $166.10 \Omega$. This result is attributed to the fact that the poly(PPA) is not a good conductor compared with GNPs and $\mathrm{NiO}$ which can obstruct the electron transfer of redox probe $\left[\mathrm{Fe}(\mathrm{CN})_{6}\right]^{3-/ 4-}$. Therefore, the impedance value increased for ITO/poly (PPA). After the poly(PPA) was deposited onto the ITO/GNPs/NiO electrode, the $R_{\mathrm{CT}}$ value for ITO/ GNPs/NiO/poly(PPA) decreased from 24.34 to $20.12 \Omega$, implying that $\mathrm{NiO}$ facilitates the electron transfer between the redox probe and the electrode (Figure 4b).

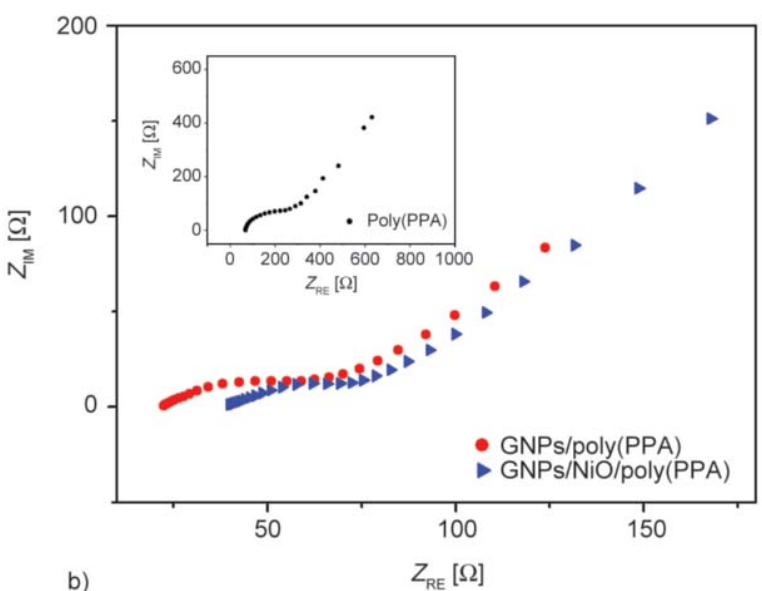

b)

Figure 4. Electrochemical impedance spectra for a) bare ITO, ITO/GNPs, and ITO/GNPs/NiO, b) ITO/GNPs/NiO/poly(PPA), $\mathrm{ITO} / \mathrm{GNPs} /$ poly(PPA), and ITO/poly(PPA) in $10.0 \mathrm{mM}\left[\mathrm{Fe}(\mathrm{CN})_{6}^{3-/ 4-}\right]$ redox probe containing $0.1 \mathrm{M} \mathrm{KCl}$ in the frequency range $10^{5}-0.1 \mathrm{~Hz}$. The AC voltage amplitude was $10 \mathrm{mV}$ and the applied potential was $200 \mathrm{mV}$ 


\subsection{Redox behavior of}

ITO/GNPs/NiO/poly(PPA) electrode in PBS

The redox behavior of ITO/GNPs/NiO/poly(PPA) was compared with that of ITO/GNPs/poly(PPA) to investigate the effect of $\mathrm{NiO}$. Figure $5 \mathrm{a}$ represents the cyclic voltammograms of ITO/GNPs/poly(PPA) and ITO/GNPs/NiO/Poly(PPA), and the inset of Figure $5 \mathrm{a}$ shows the cyclic voltammograms of ITO/ GNPs/poly(PPA) and ITO/poly(PPA) in $0.02 \mathrm{M} \mathrm{PBS}$ $(\mathrm{pH}=7)$ at a scan rate of $100 \mathrm{mV} \cdot \mathrm{s}^{-1}$. As shown in the inset of Figure $5 \mathrm{a}$, no clear electrochemical response was observed at poly(PPA) for the neutral solution, indicating the absence of reaction peak current in the scanning potential range. The $\mathrm{CV}$ of the ITO/GNPs/ poly(PPA) electrode (Figure 5a inset) exhibited peaks at $\sim 0.42$ and $\sim 0.94 \mathrm{~V}$, which corresponded to two well-established redox couples of electro-reduction and electro-oxidation of $\mathrm{Au}$ [48]. A pair of well-defined redox peak couples were also observed for ITO/GNPs/ NiO/poly(PPA), with an enhanced redox activity (the peak currents were obviously enhanced nearly ten times when compared to ITO/GNPs/poly (PPA)), which can be related to the strong effect of the modification of $\mathrm{NiO}$ that can intensify currents due to the contribution of a redox couple $\left(\mathrm{Ni}^{2+} \leftrightarrow \mathrm{Ni}^{3+}\right)$ of $\mathrm{NiO}$ [49] (Figure 5a).

The influence of potential scan rate on the electrochemical behavior of ITO/GNPs/NiO/poly(PPA) and ITO/GNPs/poly(PPA) was also investigated. The redox behavior of GNPs/NiO/poly(PPA) is given in Figure $5 b$, and the inset of Figure $5 b$ shows ITO/ GNPs/poly(PPA) obtained at different scan rates in $0.02 \mathrm{M}$ PBS $(\mathrm{pH}=7)$. As shown in Figure 5b, the peak currents linearly increased with the scan rate, which ranged from 50 to $500 \mathrm{mV} \cdot \mathrm{s}^{-1}$. The peak-to-peak separation widened with the increase in scan rates. The effect of varying scan rate with the peak current response of modified electrodes is shown in Figure 5c. According to Figure 5c, both the anodic and cathodic peak currents are proportional with the scan rate
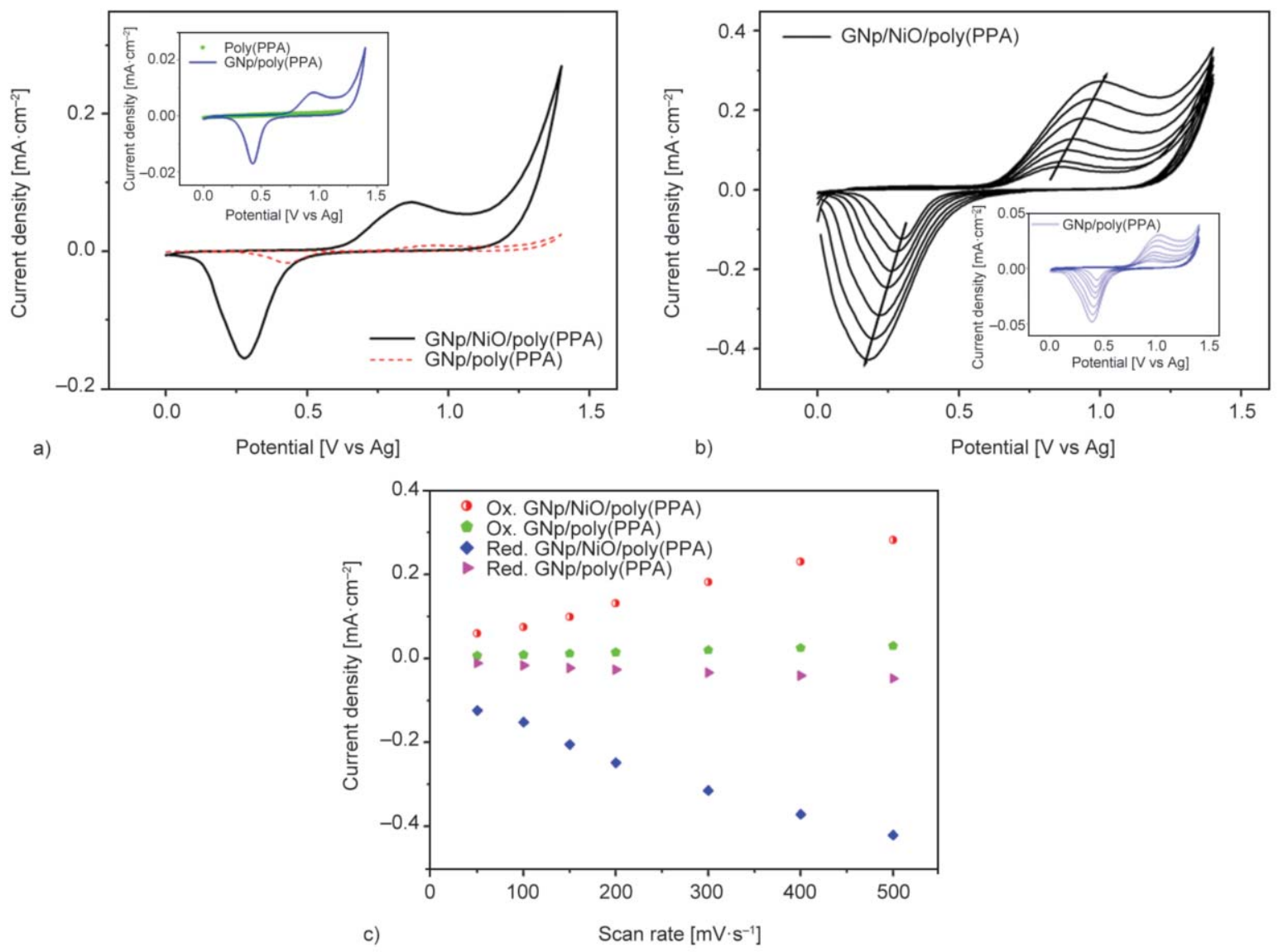

Figure 5. CV scans of a) ITO/GNPs/poly(PPA) and ITO/GNPs/NiO/Poly(PPA)-modified ITO. Inset of a) shows ITO/poly(PPA) and ITO/GNPs/Poly(PPA) at $100 \mathrm{mV} \cdot \mathrm{s}^{-1}$ in $0.02 \mathrm{M} \mathrm{PBS}(\mathrm{pH}=7)$, b) scan rate dependences of $\mathrm{CV}$ for ITO/GNPs/ $\mathrm{NiO} / \mathrm{Poly}(\mathrm{PPA})$; inset of b) shows scan rate dependences of CV for ITO/GNPs/Poly(PPA) scan rate: 50, 100, 150, $200,300,400,500 \mathrm{mV} \cdot \mathrm{s}^{-1}$ in $\left.0.02 \mathrm{M} \mathrm{PBS}(\mathrm{pH}=7), \mathrm{c}\right)$ anodic and corresponding cathodic peak current vs. scan rate of ITO/GNPs/poly(PPA) and ITO/GNPs/NiO/Poly(PPA) 
(correlation coefficients of $R_{\mathrm{An}}=0.9988$ and $R_{\mathrm{Cat}}=$ 0.9976 for $\mathrm{ITO} / \mathrm{GNPs} / \mathrm{NiO} /$ poly $(\mathrm{PPA})$ and $R_{\mathrm{An}}=$ 0.9991 and $R_{\text {Cat }}=0.9939$ for ITO/GNPs/Poly(PPA) in the range of 50 to $500 \mathrm{mV} \cdot \mathrm{s}^{-1}$ (Figure $5 \mathrm{c}$ ). These findings indicate that electrochemical processes are surface controlled [50].

\subsection{Interfacial properties of ITO/GNPs/NiO/poly(PPA) electrode/electrolyte}

M-S analysis provides important information about the semiconducting properties of modified electrodes in contact with electrolytes, and it is commonly used to estimate the dopant density and flat band potential of a semiconductor/electrolyte interface. Charges are transferred between the semiconductor and the solution phase when they come into contact [51]. M-S analysis occurred through the graphing of the inverse square of space-charge capacitances $\left(1 / C_{\mathrm{SC}}{ }^{2}\right)$ against the various applied potentials. M-S analysis was performed in an aqueous solution of $1 \mathrm{M} \mathrm{Na}_{2} \mathrm{SO}_{4}$. The M-S plots of ITO/NiO, ITO/GNPs/NiO, ITO/GNPs/ poly(PPA), and ITO/GNPs/NiO/poly(PPA) are shown in Figure 6. The M-S equation can be expressed in Equation (1) [52]:

$\frac{1}{C_{\mathrm{SC}}^{2}} A^{2}=\left(\frac{2}{\varepsilon \varepsilon_{\mathrm{p}} e N_{\mathrm{D}}}\right)\left(E-E_{\mathrm{FB}}-\frac{k_{\mathrm{B}} T}{e}\right)$

where $C_{\mathrm{SC}}$ is the space-charge capacitance, $A$ is the area, $N_{\mathrm{D}}$ is the carrier density, $E$ is the applied voltage, $E_{\mathrm{FB}}$ is the flat band potential, $k_{\mathrm{B}}$ is Boltzmann's constant, $T$ is the absolute temperature, $e$ is the electronic charge, $\varepsilon$ is the vacuum permittivity, $\varepsilon_{\mathrm{p}}$ is relative permittivity of $\mathrm{NiO}$ or poly (PPA), and $N_{\mathrm{D}}$ is the carrier density. In the present study, we assumed $\varepsilon_{\mathrm{p}}$ was 10 for poly(PPA) and 12 for $\mathrm{NiO}[53,54]$. It was reported in the literature that $\mathrm{NiO}$ exhibits $p$-type conductivity [55]. In this study, the resulting $\mathrm{NiO}$ was a $p$-type semiconductor, presenting negative slope in the linear region of the M-S plot. The negative slope of the M-S plot also revealed that the GNPs/poly(PPA) and GNPs/NiO/poly(PPA) hybrid electrodes were $p$-type semiconductors (Figue $6 \mathrm{~b}$ ). $N_{\mathrm{D}}$ was calculated from the slope of the M-S plot. The results are shown in Table 1. GNPs/NiO showed remarkably higher slopes in the M-S plot as compared to $\mathrm{NiO}$, indicating a lower value of $C_{\mathrm{SC}}$ at the GNPs/NiO-electrolyte interface than at the NiO-electrolyte interface [56]. The $N_{\mathrm{D}}$ of $\mathrm{NiO}$ and $\mathrm{GNPs} / \mathrm{NiO}$ was $3.48 \cdot 10^{21}$ and $0.24 \cdot 10^{21} \mathrm{~cm}^{-3}$, respectively. The GNPs $/ \mathrm{NiO} /$ poly(PPA) $\left(2.48 \cdot 10^{21} \mathrm{~cm}^{-3}\right)$ electrode showed slightly higher carrier concentration than that of GNPs/ poly(PPA) $\left(2.19 \cdot 10^{21} \mathrm{~cm}^{-3}\right)$ (Table 1). The flat band potential $\left(E_{\mathrm{FB}}\right)$ of the semiconductor is provided as the intersecting $E$-axis of the plot. $E_{\mathrm{FB}}$ for GNPs/poly (PPA) was $0.25 \mathrm{~V}$ and $E_{\mathrm{FB}}$ of $\mathrm{GNPs} / \mathrm{NiO} /$ poly $(\mathrm{PPA})$ was $0.26 \mathrm{~V}$. The values of $N_{\mathrm{D}}$ and $E_{\mathrm{FB}}$ for ITO/GNPs/ $\mathrm{NiO} /$ poly(PPA) and ITO/GNPs/poly(PPA) were very similar, indicating that the last coated poly(PPA) film manifested the interfacial properties.

Table 1. Semiconducting parameter of modified electrode

\begin{tabular}{|l|c|c|c|}
\hline \multicolumn{1}{|c|}{ Modifed ITO } & $\begin{array}{c}\boldsymbol{E}_{\mathbf{F B}} \\
{[\mathbf{V}]}\end{array}$ & $\begin{array}{c}\boldsymbol{N}_{\mathbf{D}} \cdot \mathbf{1 0}^{\mathbf{2 1}} \\
{\left[\mathbf{c m}^{-\mathbf{3}}\right]}\end{array}$ & $\begin{array}{c}\text { Carrier } \\
\text { type }\end{array}$ \\
\hline $\mathrm{NiO}$ & 0.29 & 3.48 & $p$ \\
\hline GNPs/NiO /poly(PPA) & 0.26 & 2.48 & $p$ \\
\hline GNPs/ poly(PPA) & 0.25 & 2.19 & $p$ \\
\hline GNPs $/ \mathrm{NiO}$ & 0.27 & 0.24 & $p$ \\
\hline
\end{tabular}

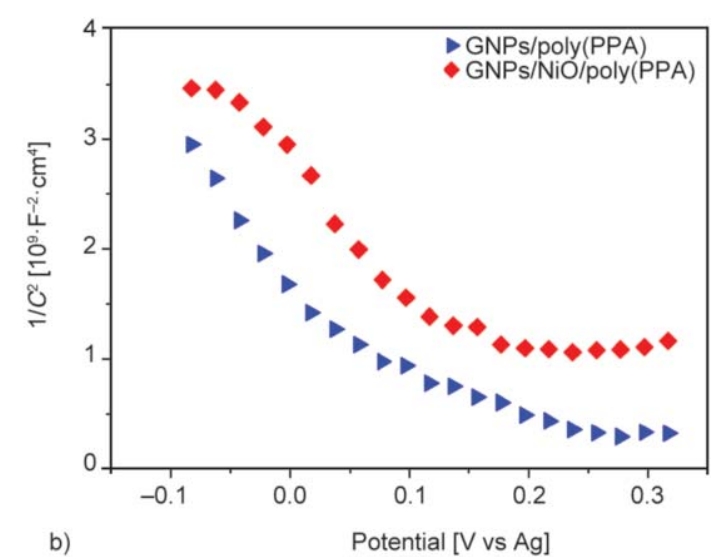

Figure 6. M-S plots for modified electrodes a) ITO/GNPs/NiO and ITO/NiO -inset corresponds to NiO and b) ITO/GNPs/ poly(PPA) and ITO/GNPs/NiO/poly(PPA) 


\subsection{Spectroscopic, structural, and morphologic characterization of fabricated electrodes and tyrosinase immobilization}

Figure 7 shows the XRD patterns of the $\mathrm{NiO}$ film. The peaks at $38.19,44.1,64.61,75.38$, and $77.45^{\circ}$ can be assigned to (111), (200), and (220) (311) (222) reflections of cubic the NiO phase [57]. The FTIR ATR spectra of $\mathrm{NiO}$, poly(PPA), GNPs/NiO/poly (PPA), GNPs/poly(PPA)-Ty, and GNPs/NiO/poly (PPA)-Ty are shown in Figure 8. As shown in Figure $8 \mathrm{a}, \mathrm{NiO}$ exhibited a weak absorbance peak at $3311 \mathrm{~cm}^{-1}$, related to the stretching vibration of the interlayer water molecule [58] The peaks at 1246, 903 , and $786 \mathrm{~cm}^{-1}$ are attributed to the stretching band of $\mathrm{NO}_{3}$ [59]. The weak peak of stretching vibration at $413 \mathrm{~cm}^{-1}$ can be attributed to nickel-oxygen interaction. The strong peak at $638 \mathrm{~cm}^{-1}$ belongs to the formation of hydroxide phase [46]. The Raman spectrum of $\mathrm{NiO}$ is shown in the inset of Figure 8a. The bands at $564 \mathrm{~cm}^{-1}$ indicated the presence of $\mathrm{NiO}$ [58]. As shown in Figure 8b, the strong peak observed at $1704 \mathrm{~cm}^{-1}$ belongs to the $\mathrm{C}=\mathrm{O}$ vibration of the carboxylic acid substituent of the pyrrole ring. The absorbance peaks observed at 1550 and $1393 \mathrm{~cm}^{-1}$ are attributed to the stretching vibrations of the $\mathrm{C}-\mathrm{C}$, $\mathrm{C}=\mathrm{C}$ and $\mathrm{C}-\mathrm{N}$ groups in the PPy ring, respectively [60]. The peak at $1181 \mathrm{~cm}^{-1}$ is attributed to $\mathrm{C}-\mathrm{H}$ or $\mathrm{C}-\mathrm{N}$ in-plane vibration [61]. The bands at 912 and $771 \mathrm{~cm}^{-1}$ were attributed to the $=\mathrm{C}-\mathrm{H}$ in-plane vibration and out-of-plane vibration, respectively [62]. The strong absorption bands at $1086 \mathrm{~cm}^{-1}$ indicate that poly(PPA) film is highly doped with the anion of $\mathrm{ClO}_{4}^{-}$[63]. GNPs/NiO/poly(PPA)-Ty and GNPs/ poly(PPA)-Ty samples showed new peaks around

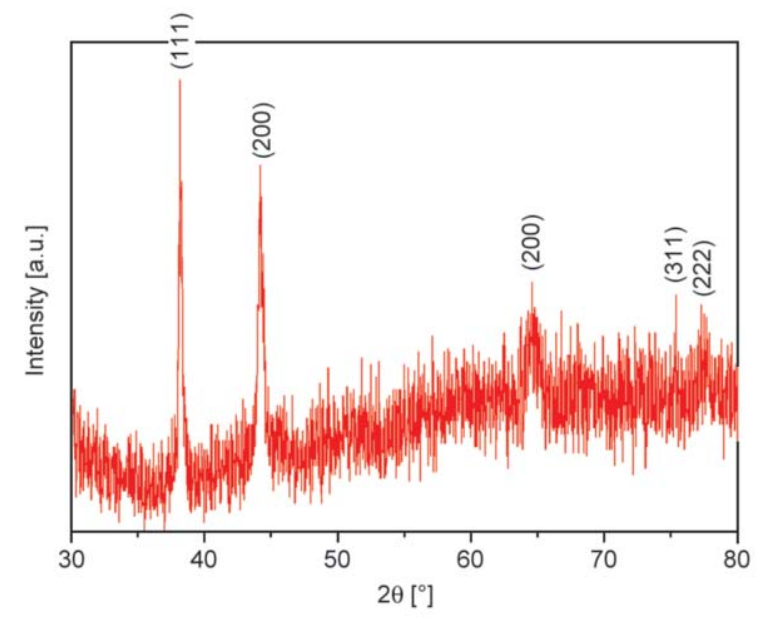

Figure 7. XRD pattern of $\mathrm{NiO}$ film
$1710-1590$ and $1510-1490 \mathrm{~cm}^{-1}$, which is characteristic of the $-\mathrm{C}=\mathrm{O}$ stretching of amide $\mathrm{I}$ and the $\mathrm{N}-\mathrm{H}$ bending of amide II for the - $\mathrm{CO}-\mathrm{NH}$ - bond formed between the enzyme and polymer, respectively (Figure 8c) [64].

SEM and AFM measurements were performed to investigate the surface modification process and to monitor the success of enzyme immobilization. SEM images of ITO/GNPs, ITO/GNPs/NiO, ITO/GNPs/ poly(PPA), ITO/GNPs/NiO/poly(PPA), ITO/GNPs/ poly(PPA)-Ty, and ITO/GNPs/NiO/poly(PPA)-Ty are shown in Figure 9. As shown in Figure 9a, GNPs with a quasi-spherical shape were covered with a relatively
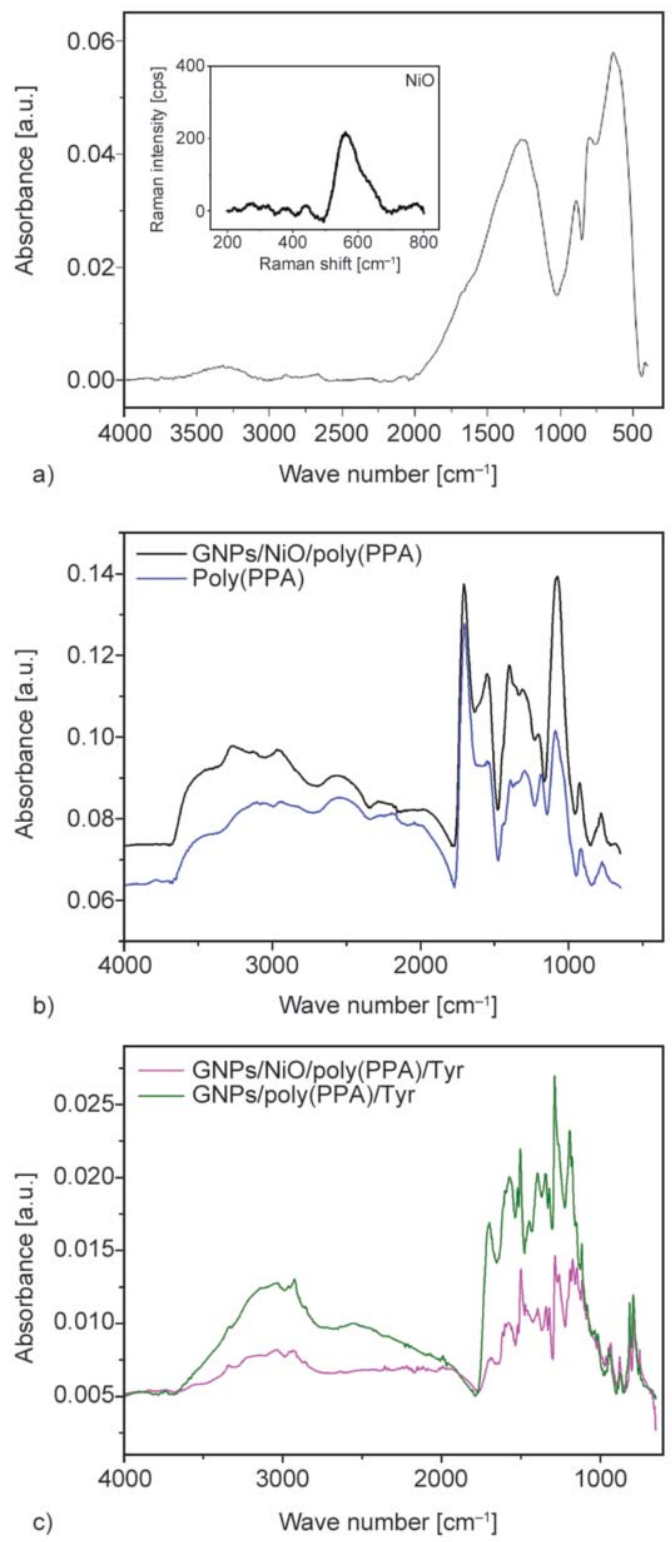

Figure 8. FTIR-ATR spectra of a) NiO b) poly(PPA), GNPs/ $\mathrm{NiO} /$ poly(PPA), and c) GNPs/poly(PPA)-Ty and GNPs/NiO/poly(PPA)-Ty; the inset of a) shows the Raman spectrum of $\mathrm{NiO}$ 


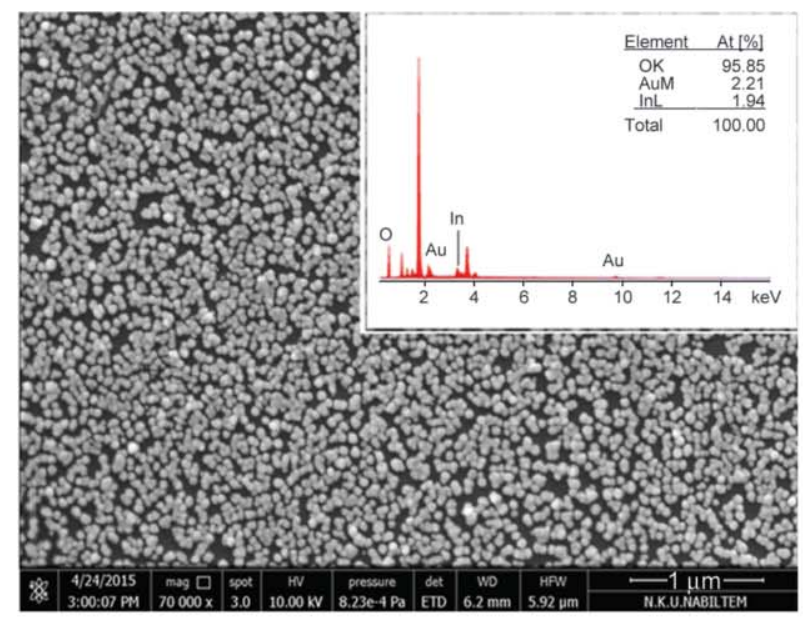

a)

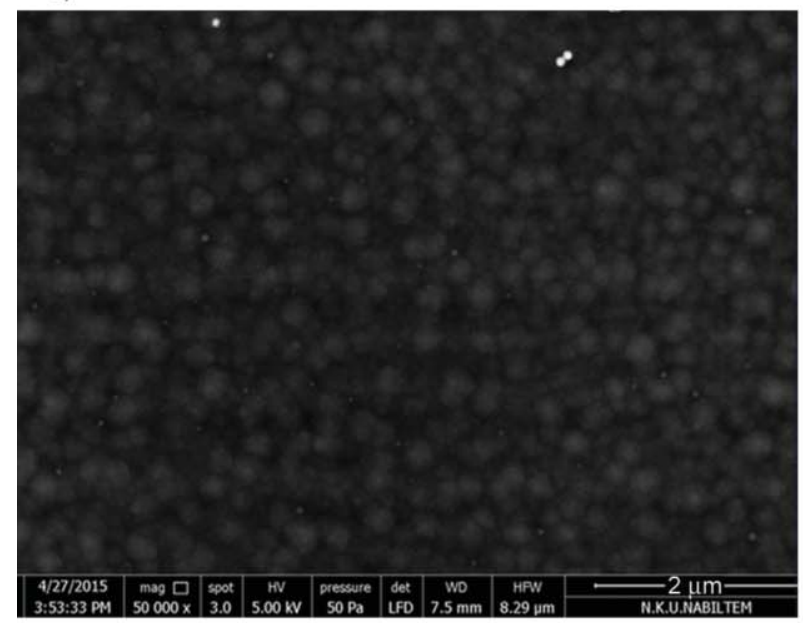

c)

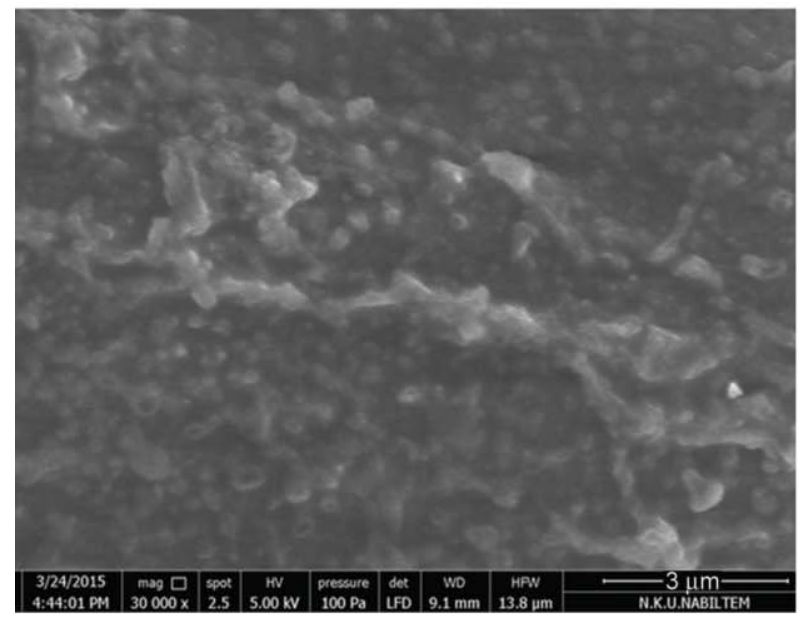

e)

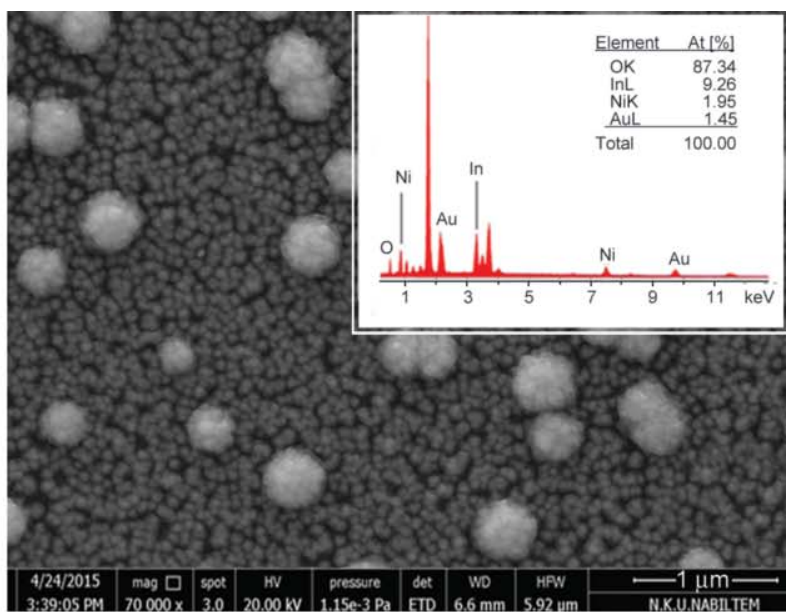

b)

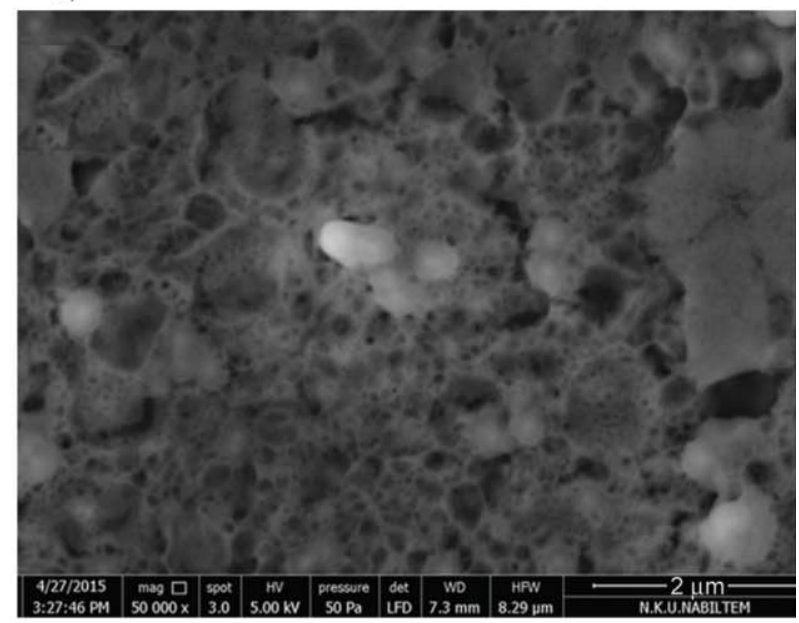

d)

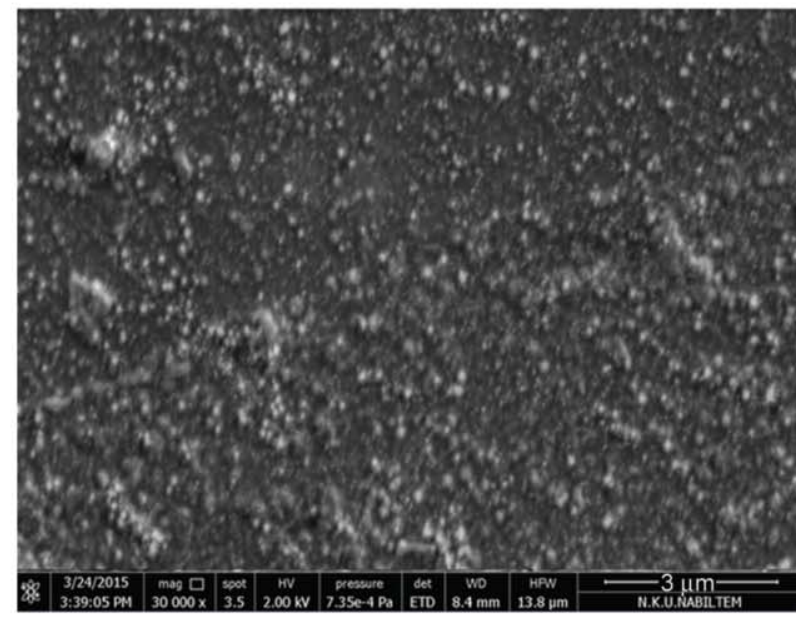

f)

Figure 9. SEM images of a) ITO/GNPs, b) ITO/GNPs/NiO, c) ITO/GNPs/poly(PPA), d) ITO/GNPs/NiO/poly(PPA) e) ITO/GNPs/poly(PPA)-Ty, and f) ITO/GNPs/NiO/poly(PPA)-Ty; insets show EDS spectrum

uniform distribution and with an average particle size of $74.49 \mathrm{~nm}$, measured by using ImageJ1.48v. The deposition of $\mathrm{NiO}$ on top of the GNP-modified ITO, as shown in Figure 9b, resulted in large spherical nano-agglomerates. They did not cover an entire portion of the GNPs and were located sparsely on top of the GNPs. The growth characteristic of $\mathrm{NiO}$ was found to be enlarged to $357.96 \mathrm{~nm}$. The GNPs and GNPs/NiO were also characterized by the EDS to show the presence of GNPs and NiO in the modification process (see inset in Figure 9a, and 9b). The results revealed the presence of $\mathrm{Au}, \mathrm{Ni}$, and oxygen, and this further confirmed the existence of GNPs and $\mathrm{NiO}$ in the electrode assembly. Figure $9 \mathrm{c}$ and $9 \mathrm{~d}$ 
show the SEM image of poly(PPA) films onto the ITO/GNPs and ITO/GNPs/NiO electrodes. The image of poly(PPA) film onto GNPs (Figure 9c) showed a homogeneous morphology with a spherical granular shape covering the GNPs, whereas the image of poly(PPA) film onto GNPs/NiO showed porous structures (Figure 9d). Images of immobilized Ty onto GNPs/poly(PPA) and GNPs/NiO/ poly (PPA) are shown in Figures 9e, and 9f. The enzyme-immobilized electrodes showed a very distinctive structure as compared to that of pure ITO/GNPs/ poly(PPA) and ITO/GNPs/NiO/poly(PPA). ITO/GNPs/poly (PPA)-Ty displays a swelled spherical granular-like structure as compared to the non-immobilized polymer matrix (ITO/GNPs/poly(PPA)), and the diameter of granules is larger than that of ITO/GNPs/ poly(PPA) (Figure 9e). After immobilization of the Ty onto the ITO/GNPs/NiO/poly(PPA), the pores of ITO/GNPs/ $\mathrm{NiO} /$ poly(PPA) disappeared, and the enzyme-loaded swelled granules were observed clearly on the ITO/ GNPs/NiO/poly(PPA)-Ty electrode (Figure 9f). These results confirm that Ty was successfully immobilized onto the ITO/GNPs/poly(PPA) and ITO/GNPs/NiO/ poly(PPA) electrodes.

The two-dimensional (2D) and three-dimensional (3D) surface topographies of modified electrodes are illustrated in Figure 10. Modification of the ITO surface results in variation in surface topographies. The RMS surface roughness value of bare ITO (the graph is not shown here) increased from 4.34 to $23.01 \mathrm{~nm}$ with the modification of GNPs (Figure 10a). The other RMS surface roughness values were 10.57, 10.72, and $21.31 \mathrm{~nm}$ for ITO/GNPs/poly (PPA), ITO/ $\mathrm{GNPs} / \mathrm{NiO}$, and ITO/GNPs/NiO/poly (PPA), respectively. The roughness changed from 10.57 (ITO/GNPs/ poly(PPA)) to $14.21 \mathrm{~nm}$ (Figure 10e) and from 21.31 (ITO/GNPs/NiO/poly(PPA)) to $8.62 \mathrm{~nm}$ (Figure 10f) after Ty immobilization onto the electrodes. The

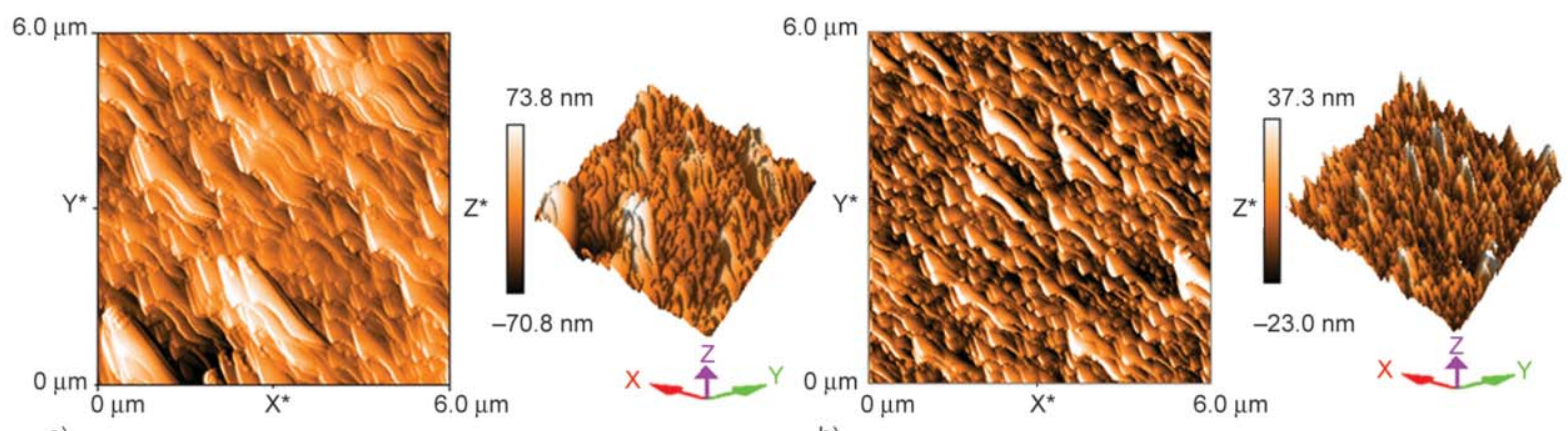

a)

b)
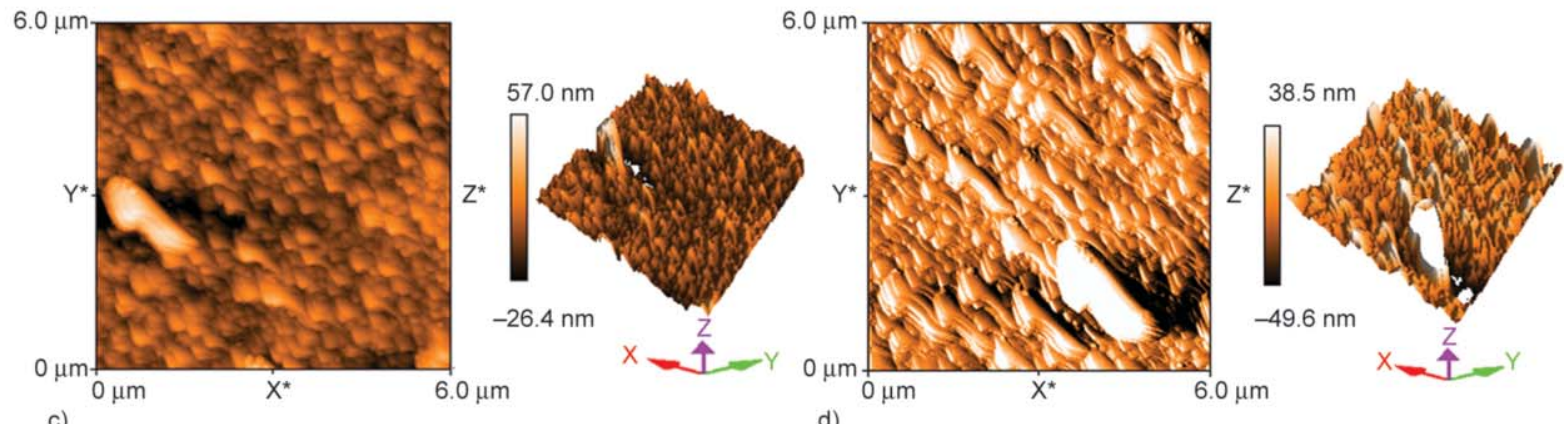

c)

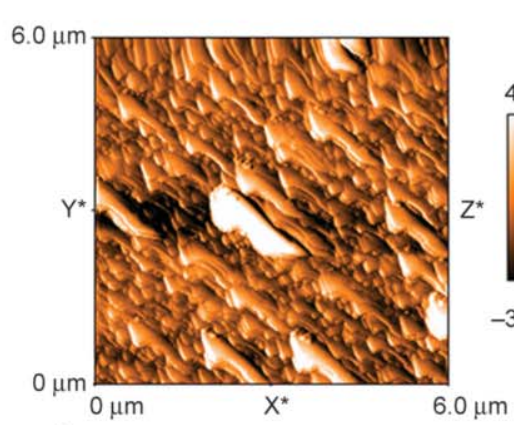

e)
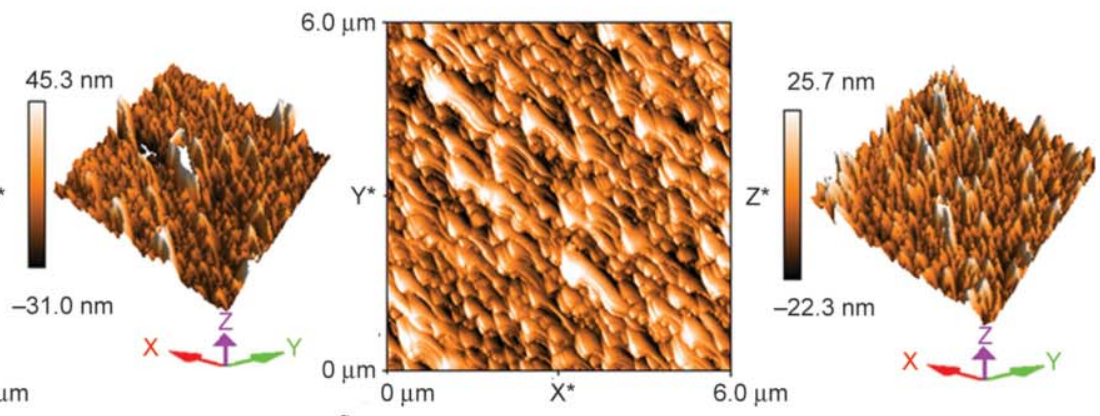

Figure 10. 2D-3D AFM topographies of a) ITO/GNPs, b) ITO/GNPs/NiO, c) ITO /GNPs/poly(PPA), d) ITO/GNPs/NiO/ poly(PPA), e) ITO/GNPs/poly(PPA)-Ty, and f) ITO/GNPs/NiO/poly(PPA)-Ty 
change in surface roughness also confirmed that the Ty immobilization onto the ITO/GNPs/NiO/poly (PPA) and ITO/GNPs/poly(PPA) electrodes was successful.

\subsection{Electrochemical impedance spectroscopy study of Ty based electrode (ITO/GNPs/NiO/poly(PPA)-Ty)}

EIS is a versatile technique describing the response of an electrochemical process taking place at the electrode solution interface [65]. It has been demonstrated that EIS measurements can provide significantly more sensitive responses than amperometric techniques for the detection of some biomolecules $[66,67]$. To investigate the dopamine (DP) sensing characteristics of the ITO/GNPs/NiO/poly(PPA)-Ty, EIS was performed in the frequency range $100 \mathrm{mHz}$ to $10^{5} \mathrm{~Hz}$. The optimal working potential was set to $+0.200 \mathrm{~V}$. Dopamine (from $80 \mu \mathrm{M}$ to $1.2 \mathrm{mM}$ ) was injected into the $0.1 \mathrm{M}$ PBS $(\mathrm{pH}=7.4)$ containing $2.5 \mathrm{mM}\left[\mathrm{Fe}(\mathrm{CN})_{6}^{3-/ 4-}\right]$ redox probe In order to represent the variation of the impedance with variation of dopamine concentrations, the Nyquist and Bode Magnitude plots of the ITO/GNPs/NiO/poly(PPA)Ty after exposure to different concentration of dopamine have been provided in Figure 11. As shown in Figure 11a, The Nyquist plot presents a semicircle region at the high frequency region due to the electron transfer process, followed by a straight line due to diffusion transfer limited process. Bode magnitude plots given in Figure 11b. Considerable changes were obtained in the $|Z|$ values with the variation of dopamine concentration at the frequency of below

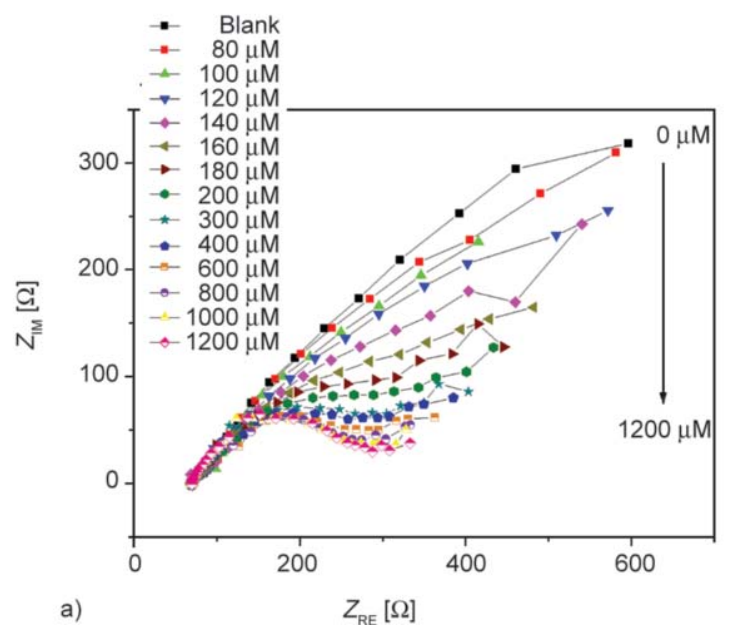

$150 \mathrm{~Hz}$. However, negligible changes were observed in the $|Z|$ values in the high frequency region for the ITO/GNPs/NiO/poly(PPA)-Ty, showing a purely resistive behavior due to the presence of solution resistance $R_{\mathrm{S}}$ [68]. Figure 12 shows the Bode phase plot. In the intermediate frequency region, a phase angle, reached greater than $30^{\circ}$ but less than $90^{\circ}$, was observed to increase, and shifted with increasing concentration of dopamine to higher value of frequency, indicating a dielectric pseudo capacitive behavior at the bioelectrode/solution interface [68, 69].

The of $\mathrm{R}(\mathrm{Q}(\mathrm{RW}))$, given in inset Figure 12, comprises a solution resistance $\left(R_{\mathrm{S}}\right)$, a charge transfer resistance $\left(R_{\mathrm{CT}}\right)$, a constant phase element (CPE) used instead of $C_{\mathrm{dl}}$ in equivalent circuit due to inhomogeneous electrode, roughness or fractional geometry and electrode porosity [70], and Warburg element $(W)$ was used to fit impedance diagrams.

CPE can be represented by Equation (2)

$Z_{\mathrm{CPE}}=\frac{1}{Y_{0}(j \omega)^{\mathrm{n}}}$

where $j$ is $\sqrt{(-1)}, Y_{0}$ is CPE parameter which is frequency-independent, $\omega$ is the angular frequency [71], and $\mathrm{n}$ describes the deviation from an ideal capacitor and arises from the slope of the $\log Z$ versus $\log f$ plot. If an $n$ value is $0, Z_{\mathrm{CPE}}$ corresponds to a pure resistor; when $\mathrm{n}$ is $0.5, Z_{\mathrm{CPE}}$ denotes Warburg behavior [72], while $n=1, Z_{\mathrm{CPE}}$ represents an ideal capacitor. The deviation of frequency $(\omega)$ exponent $n$ from ideal values, where $n$ is equal to 1 for a smooth surface, is attributed to the inhomogeneities of analyzed layer, such as roughness or defects.

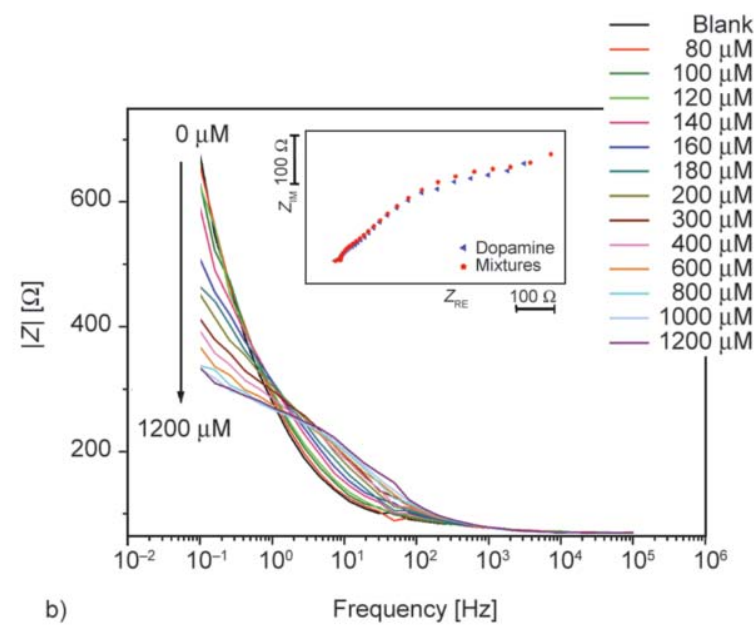

Figure 11. a) Nyquist b) Bode magnitude plots of ITO/GNPs/NiO/poly(PPA)-Ty electrode in PBS $(0.1 \mathrm{M}$ pH = 7.4) buffer solution at various dopamine concentrations containing $2.5 \mathrm{mM}\left[\mathrm{Fe}(\mathrm{CN})_{6}^{3-/ 4-}\right]$ redox probe; frequency range was $10^{5}-0.1 \mathrm{~Hz}$. The $\mathrm{AC}$ voltage amplitude was $10 \mathrm{mV}$, and $E_{\mathrm{DC}}=0.2 \mathrm{~V}$; Inset of b) shows the selectivity of ITO/GNPs/poly(PPA)-Ty electrode. 


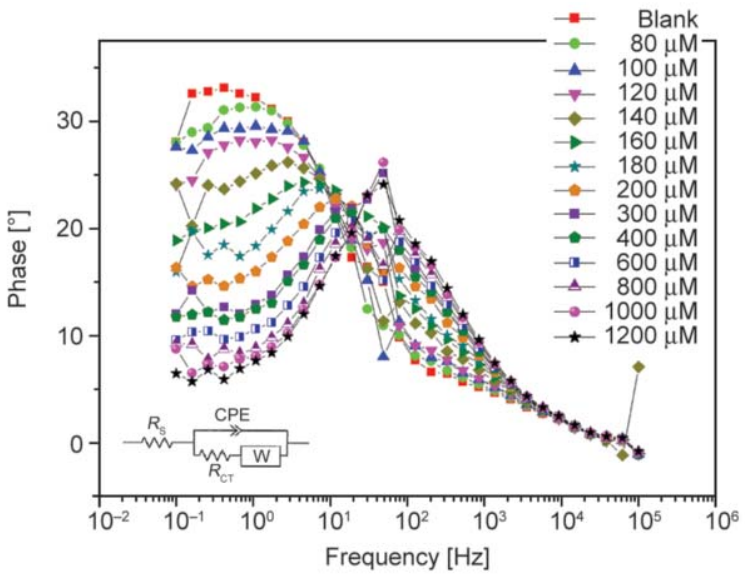

Figure 12. Bode phase plots of GNPs/NiOx/poly(PPA)-Ty electrode in PBS $(0.1 \mathrm{M} \mathrm{pH}=7.4)$ buffer solution at various dopamine concentrations containing $2.5 \mathrm{mM}\left[\mathrm{Fe}(\mathrm{CN})_{6}^{3-/ 4-}\right]$ redox probe; frequency range was $10^{5}-0.1 \mathrm{~Hz}$. The AC voltage amplitude was $10 \mathrm{mV}$, and $E_{\mathrm{DC}}=0.2 \mathrm{~V}$.

The impedance parameters extracted from equivalent circuit modeling using the software ZSimpWin V3.22 are given in Table 2. A Small Chi-squared function $\left(\chi^{2}\right)$ is found in the order of $10^{-4}$ suggesting an appropriate equivalent circuit. A comparison the changes in the values of different circuit elements after each obtained impedance spectrum with subsequent addition of dopamine are shown in Table 2. The values of $R_{\mathrm{CT}}$ decrease with the increasing concentration of dopamine as shown in Table 2. In an enzymatic reaction, the generated electrons during the oxidation of DA are transferred to ferricyanide ion. Thus, ferricyanide is reduced to ferrocyanide. Ferrocyanide is finally oxidized to ferricyanide at the electrode surface. The change in the $R_{\mathrm{CT}}$ value during DA detection arises from generation of electrons during enzymatic reaction, and hence, reduction of ferricyanide to ferrocyanide [73]. A decrease in $Y_{0}$ value was also observed with subsequent addition of dopamine, indicating a decrease in capacitive behavior of the ITO/GNPs/ NiO/poly(PPA)-Ty bioelectrode (Table 2) [69].

The calibration curve is constructed using the charge transfer resistances $\left(\Delta R_{\mathrm{CT}}=R_{\mathrm{CTBlank}}-R_{\mathrm{CTn}}\right)$ (Figure 13), and using the modulus of impedance $(|Z|)$ which result at a frequency of $11.72 \mathrm{~Hz}$ from the Bode magnitude plot vs. concentration of dopamine. A linear relationship between change in $\Delta R_{\mathrm{CT}}$ and $|Z|$ concentration of DA $(80 \mu \mathrm{M}-0.2 \mathrm{mM}$ ) has been observed (Figure 13) with best fitting to the linear regression equation of $\Delta R_{\mathrm{CT}}\left[\mathrm{k} \Omega \cdot \mathrm{cm}^{2}\right]=$ $0.681-1.20 \cdot 10^{-2} \cdot C /(\mu \mathrm{M})$, with a correlation coefficient $\left(R^{2}\right)$ of 0.95 , and $|Z|\left[\mathrm{k} \Omega \cdot \mathrm{cm}^{2}\right]=$ $0.087+4.16 \cdot 10^{-4} \cdot C /(\mu \mathrm{M})$ with a correlation coefficient $\left(R^{2}\right)$ of 0.98 . The sensitivity of the ITO/GNPs/ $\mathrm{NiO} /$ poly(PPA)-Ty electrode was determined as $1.20 \cdot 10^{-2} \mathrm{k} \Omega \cdot \mathrm{cm}^{2} / \mu \mathrm{M}$. The LOD was calculated from the standard deviation of blank signal $\left(S_{\mathrm{B}}\right)$ and slope of calibration curve (b) using the equation of $3 S_{\mathrm{B}} / \mathrm{b}$, which was $5.46 \mu \mathrm{M}$.

The selectivity of ITO/GNPs/NiO/poly(PPA)-Ty bioelectrode (inset in Figure 11b) studied in presence of DA $(100 \mu \mathrm{M})$ with the equal molar of interferents which are ascorbic acid $(100 \mu \mathrm{M})$ and glucose $(100 \mu \mathrm{M})$. ITO/GNPs/NiO/poly(PPA)-Ty bioelectrode is not significantly affected in the presence of

Table 2. The system parameters obtained arising from the fitting of the Nyquist diagram of ITO/GNPs/NiO/poly(PPA)-Ty electrode with the equivalent circuit of $\mathrm{R}(\mathrm{Q}(\mathrm{RW})$ concentration range of $0-1200 \mu \mathrm{M}$

\begin{tabular}{|r|c|c|c|c|c|c|}
\hline $\begin{array}{r}{[\mathbf{D A}]} \\
{[\boldsymbol{\mu} \mathbf{M}]}\end{array}$ & $\begin{array}{c}\boldsymbol{R}_{\mathbf{s}} \\
{\left[\boldsymbol{\Omega} \cdot \mathbf{c m}^{2}\right]}\end{array}$ & $\begin{array}{c}\mathbf{Q}(\mathbf{C P E})\left(\boldsymbol{Y}_{\mathbf{0}} / \mathbf{S}\right) \\
{\left[\mathbf{s}^{\mathbf{- n}} \cdot \mathbf{c m}^{-2}\right]}\end{array}$ & $\boldsymbol{n}$ & $\begin{array}{c}\boldsymbol{R}_{\mathbf{C T}} \\
{\left[\mathbf{k} \boldsymbol{\Omega} \cdot \mathbf{c m}^{2}\right]}\end{array}$ & $\begin{array}{c}\boldsymbol{W}\left(\boldsymbol{Y}_{\mathbf{0}} / \mathbf{S}\right) \\
{\left[\mathbf{s}^{\mathbf{- 0 . 5}} \cdot \mathbf{c m}^{-2}\right]}\end{array}$ & $\begin{array}{c}\text { Chi-squared } \\
\text { error} \cdot \mathbf{1 0}\end{array}$ \\
\hline 0 & 71.14 & $1.63 \cdot 10^{-3}$ & 0.52 & 1.97 & $1.91 \cdot 10^{-2}$ & 14.70 \\
\hline 80 & 70.81 & $1.53 \cdot 10^{-3}$ & 0.52 & 1.62 & $1.38 \cdot 10^{-1}$ & 14.00 \\
\hline 100 & 69.84 & $1.54 \cdot 10^{-3}$ & 0.60 & 1.51 & $3.27 \cdot 10^{-2}$ & 14.80 \\
\hline 120 & 70.46 & $1.48 \cdot 10^{-3}$ & 0.49 & 1.33 & $1.04 \cdot 10^{+3}$ & 8.22 \\
\hline 140 & 69.29 & $1.31 \cdot 10^{-3}$ & 0.48 & 0.88 & $2.69 \cdot 10^{-2}$ & 11.10 \\
\hline 160 & 68.43 & $1.00 \cdot 10^{-3}$ & 0.50 & 0.52 & $7.92 \cdot 10^{-3}$ & 5.56 \\
\hline 180 & 68.80 & $8.02 \cdot 10^{-4}$ & 0.53 & 0.41 & $1.02 \cdot 10^{-3}$ & 8.17 \\
\hline 200 & 69.16 & $6.30 \cdot 10^{-4}$ & 0.55 & 0.34 & $9.37 \cdot 10^{-3}$ & 8.43 \\
\hline 300 & 68.82 & $4.17 \cdot 10^{-4}$ & 0.59 & 0.27 & $1.08 \cdot 10^{-2}$ & 7.06 \\
\hline 400 & 68.40 & $4.71 \cdot 10^{-4}$ & 0.58 & 0.23 & $1.30 \cdot 10^{-2}$ & 7.70 \\
\hline 600 & 68.41 & $3.88 \cdot 10^{-4}$ & 0.59 & 0.24 & $1.52 \cdot 10^{-2}$ & 7.44 \\
\hline 800 & 68.35 & $3.22 \cdot 10^{-4}$ & 0.61 & 0.22 & $1.82 \cdot 10^{-2}$ & 7.23 \\
\hline 1000 & 69.02 & $2.32 \cdot 10^{-4}$ & 0.65 & 0.21 & $1.99 \cdot 10^{-2}$ & 6.12 \\
\hline 1200 & 69.16 & $2.08 \cdot 10^{-4}$ & 0.66 & 0.21 & $2.33 \cdot 10^{-2}$ & 6.19 \\
\hline
\end{tabular}



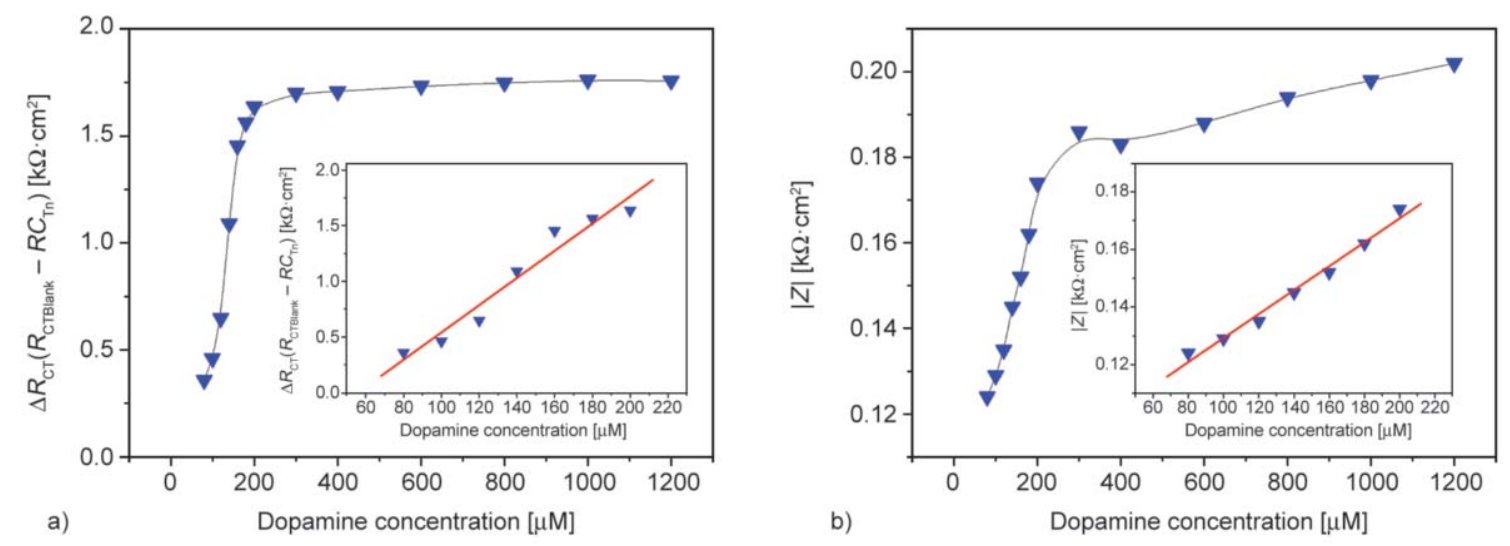

Figure 13. a) $R_{\mathrm{CTBlank}}-R_{\mathrm{CTn}}$ vs. dopamine concentration for ITO/GNPs/NiOx/poly(PPA)-Ty electrode, b) $|Z|$ vs. dopamine concentration for ITO/GNPs/NiOx/poly(PPA)-Ty electrode, concentration range $(0-1200 \mu \mathrm{M})$ insets show corresponding calibration curve

Table 3. Comparison of different tyrosinase based biosensors for DA detection

\begin{tabular}{|l|c|c|c|c|}
\hline \multicolumn{1}{|c|}{ Electrode } & Method & $\begin{array}{c}\text { Linearity } \\
{[\mathbf{M}]}\end{array}$ & $\begin{array}{c}\text { LOD } \\
{[\mathbf{M}]}\end{array}$ & Ref. \\
\hline Glutaraldehyde/Egg-shell membrane-Ty & DPV & $5 \cdot 10^{-5}-2.5 \cdot 10^{-4}$ & $2.500 \cdot 10^{-5}$ & {$[74]$} \\
\hline MEAs-SV-hfr & CA & $5 \cdot 10^{-5}-2.5 \cdot 10^{-4}$ & $1.460 \cdot 10^{-5}$ & {$[75]$} \\
\hline PEDOT-Ty & CA & $1 \cdot 10^{-5}-1.5 \cdot 10^{-4}$ & $5.580 \cdot 10^{-6}$ & {$[76]$} \\
\hline polyacrylamide microgels-Ty & CA & $1.2 \cdot 10^{-4}-3.6 \cdot 10^{-4}$ & $3.960 \cdot 10^{-5}$ & {$[77]$} \\
\hline Ty/NiO/ITOPET & CV & $2 \cdot 10^{-6}-1 \cdot 10^{-4}$ & $1.038 \cdot 10^{-6}$ & {$[78]$} \\
\hline PEDOT-CNT-Ty & CV & $1 \cdot 10^{-4}-5 \cdot 10^{-4}$ & $11.000 \cdot 10^{-6}$ & {$[79]$} \\
\hline Ty-SWNTs-Ppy & CV & $5 \cdot 10^{-6}-5 \cdot 10^{-5}$ & $5.000 \cdot 10^{-6}$ & {$[80]$} \\
\hline GNps/NiO/poly(PPA)-Ty & EIS & $8 \cdot 10^{-5}-2 \cdot 10^{-4}$ & $5.460 \cdot 10^{-6}$ & This Study \\
\hline
\end{tabular}

interferents during DP detection. The analytical performances of the proposed biosensor are comparable with other reports previously published in the literature (see Table 3).

\section{Conclusions}

GNPs/NiO/poly(PPA) multilayered film was electrochemically deposited onto the ITO substrate. The electrode assemblies were characterized by $\mathrm{CV}$, SEM-EDX, AFM, and FTIR-ATR analysis. A strong relationship was observed among electrochemical and morphological features of the modified electrodes. The $\mathrm{NiO}$ based electrodes showed improved properties compared with those of Au included alone. An M-S approach was used to examine the semiconducting properties of the modified electrodes. Covalent immobilization of Ty onto the electrodes was performed using EDC NHS chemistry. Morphologic and spectroscopic results have proven that the enzyme successfully immobilized onto the electrode. The biosensing characteristic of Ty based electrode (GNPs/ $\mathrm{NiO} /$ poly(PPA)-Ty) vs. dopamine was investigated with the equivalent circuit of $\mathrm{R}(\mathrm{Q}(\mathrm{RW}))$ using the
EIS technique. The sensitivity and LOD of the ITO/ GNPs/NiO/poly(PPA)-Ty electrode was determined as $1.20 \cdot 10^{-2} \mathrm{k} \Omega \cdot \mathrm{cm}^{2} / \mu \mathrm{M}, 5.46 \mu \mathrm{M}$, respectively. These findings demonstrate that the GNPs/NiO/poly (PPA) film is a promising electrode material to integrate enzymes via EDC NHS coupling, which could provide an analytical access to a large group of enzymes for biological applications including biosensors.

\section{Acknowledgements}

This work was supported by The Scientific \& Technological Research Council of Turkey (TUBITAK)-214Z200 Project and Istanbul Technical University Scientific Research Project (38821).

\section{References}

[1] Sadeghi S., Fooladi E., Malekaneh M.: A new amperometric biosensor based on $\mathrm{Fe}_{3} \mathrm{O}_{4}$ /polyaniline/laccase/ chitosan biocomposite-modified carbon paste electrode for determination of catechol in tea leaves. Applied Biochemistry and Biotechnology, 175, 1603-1616 (2015). https://doi.org/10.1007/s12010-014-1380-6 
[2] Mallajosyula A. T., Iyer S. S. K., Mazhari B.: Charge transport in polythiophene:fullerene:nanotube bulk heterojunction photovoltaic devices investigated by impedance spectroscopy. Current Applied Physics, 13, 677-683 (2013).

https://doi.org/10.1016/j.cap.2012.11.007

[3] Ahn S. K., Ban T., Sakthivel P., Jin S-H., Gal Y-S., Lee J. H.: Synthesis and characterization of novel crosslinkable poly(propylenedioxythiophene) derivative as a buffer layer for organic light-emitting diode applications. Macromolecular Research, 20, 459-464 (2012). https://doi.org/10.1007/s13233-012-0115-1

[4] Male U., Singu B. S., Srinivasan P.: Aqueous, interfacial, and electrochemical polymerization pathways of aniline with thiophene: Nano size materials for supercapacitor. Journal of Applied Polymer Science, 132, 42013/1-42013/8 (2015).

https://doi.org/10.1002/app.42013

[5] Kamyabi M. A., Hajari N., Turner A. P. F., Tiwari A.: A high-performance glucose biosensor using covalently immobilised glucose oxidase on a poly(2,6-diaminopyridine)/carbon nanotube electrode. Talanta, 116, 801808 (2013).

https://doi.org/10.1016/j.talanta.2013.07.068

[6] Sen T., Mishra S., Shimpi N. G.: Synthesis and sensing applications of polyaniline nanocomposites: A review. RSC Advances, 6, 42196-42222 (2016).

https://doi.org/10.1039/C6RA03049A

[7] Yao Y., Wu S-G., Xu H-H., Wang L-W.: High-sensitive glucose biosensor based on ionic liquid doped polyaniline/prussian blue composite film. Chinese Journal of Chemical Physics, 28, 755-761 (2015).

https://doi.org/10.1063/1674-0068/28/cjcp1504058

[8] Yasuzawa M., Nieda T., Hirano T., Kunugi A.: Properties of glucose sensors based on the immobilization of glucose oxidase in N-substituted polypyrrole film. Sensors and Actuators B: Chemical, 66, 77-79 (2000). https://doi.org/10.1016/S0925-4005(99)00453-0

[9] Hu Y., Zhao Z., Wan Q.: Facile preparation of carbon nanotube-conducting polymer network for sensitive electrochemical immunoassay of Hepatitis B surface antigen in serum. Bioelectrochemistry, 81, 59-64 (2011). https://doi.org/10.1016/j.bioelechem.2011.01.005

[10] Hu W., Li C. M., Cui X., Dong H., Zhou Q.: In situ studies of protein adsorptions on poly(pyrrole-co-pyrrole propylic acid) film by electrochemical surface plasmon resonance. Langmuir, 23, 2761-2767 (2007). https://doi.org/10.1021/la063024d

[11] West N., Baker P., Waryo T., Ngece F. R., Iwuoha E., Q’ Sullivan C., Karakis I.: Highly sensitive gold-overoxidized polypyrrole nanocomposite immunosensor for antitransglutaminase antibody. Journal of Bioactive and Compatible Polymers, 28, 167-177 (2013). https://doi.org/10.1177/0883911512472277
[12] Halpern A. R., Nishi N., Wen J., Yang F., Xiang C., Penner R. M., Corn R. M.: Characterization of electrodeposited gold and palladium nanowire gratings with optical diffraction measurements. Analytical Chemistry, 81, 5585-5592 (2009). https://doi.org/10.1021/ac900938t

[13] Salimi A., Hallaj R., Soltanian S.: Fabrication of a sensitive cholesterol biosensor based on cobalt-oxide nanostructures electrodeposited onto glassy carbon electrode. Electroanalysis, 21, 2693-2700 (2009).

https://doi.org/10.1002/elan.200900229

[14] Li C., Liu Y., Li L., Du Z., Xu S., Zhang M., Yin X., Wang T.: A novel amperometric biosensor based on $\mathrm{NiO}$ hollow nanospheres for biosensing glucose. Talanta, 77, 455-459 (2008).

https://doi.org/10.1016/j.talanta.2008.06.048

[15] Salimi A., Noorbakhash A., Sharifi E., Semnani A.: Highly sensitive sensor for picomolar detection of insulin at physiological $\mathrm{pH}$, using GC electrode modified with guanine and electrodeposited nickel oxide nanoparticles. Biosensors and Bioelectronics, 24, 792-798 (2008).

https://doi.org/10.1016/j.bios.2008.06.046

[16] Liu H., Wu X. L., Yang B., Li Z. J., Lei L. C., Zhang $\mathrm{X}$. W.: Three-dimensional porous $\mathrm{NiO}$ nanosheets vertically grown on graphite disks for enhanced performance non-enzymatic glucose sensor. Electrochimica Acta, 174, 745-752 (2015).

https://doi.org/10.1016/j.electacta.2015.06.062

[17] Pan L., Shen L., Li L., Zhu Q.: Synthesis of Au/NiO hollow micro-spheres and their adsorption and electrocatalytic properties for p-nitrophenol. Journal of Materials Science: Materials in Electronics, 27, 3065-3070 (2016).

https://doi.org/10.1007/s10854-015-4130-9

[18] Sun C., Wang D., Zhang M., Ni Y., Shen X., Song Y., Geng Z., Xu W., Liu F., Mao C.: Novel L-lactic acid biosensors based on conducting polypyrrole-block copolymer nanoparticles. Analyst, 140, 797-802 (2015). https://doi.org/10.1039/C4AN01602E

[19] Lata S., Batra B., Karwasra N., Pundir C. S.: An amperometric $\mathrm{H}_{2} \mathrm{O}_{2}$ biosensor based on cytochrome c immobilized onto nickel oxide nanoparticles/carboxylated multiwalled carbon nanotubes/polyaniline modified gold electrode. Process Biochemistry, 47, 992-998 (2012). https://doi.org/10.1016/j.procbio.2012.03.018

[20] Marimuthu T., Mohamad S., Alias Y.: Needle-like polypyrrole-NiO composite for non-enzymatic detection of glucose. Synthetic Metals, 207, 35-41 (2015). https://doi.org/10.1016/j.synthmet.2015.06.007

[21] Ding L., Zhao M., Ma Y., Fan S., Wen Z., Huang J., Liang J., Chen S.: Triggering interface potential barrier: A controllable tuning mechanism for electrochemical detection. Biosensors and Bioelectronics, 85, 869-875 (2016). https://doi.org/10.1016/j.bios.2016.06.009 
[22] Nandini S., Nalini S., Sanetuntikul J., Shanmugam S., Niranjana P., Melo J. S., Suresh G. S.: Development of a simple bioelectrode for the electrochemical detection of hydrogen peroxide using Pichia pastoris catalase immobilized on gold nanoparticle nanotubes and polythiophene hybrid. Analyst, 139, 5800-5812 (2014). https://doi.org/10.1039/c4an01262c

[23] Chen J., Sheng Q., Zheng J.: Dispersed gold nanoparticles on $\mathrm{NiO}$ coated with polypyrrole for non-enzymic amperometric sensing of glucose. RSC Advances, 127, 105372-105378 (2015).

https://doi.org/10.1039/c5ra20715k

[24] Harraz F. A.: Electrochemical formation of a novel porous silicon/polypyrrole hybrid structure with enhanced electrical and optical characteristics. Journal of Electroanalytical Chemistry, 729, 68-74 (2014). https://doi.org/10.1016/j.jelechem.2014.07.015

[25] Zhang L., Wan M.: Polyaniline/ $\mathrm{TiO}_{2}$ composite nanotubes. Journal of Physical Chemistry B, 107, 6748-6753 (2003). https://doi.org/10.1021/jp034130g

[26] Larsson M., Bromark M., Hedenqvist P., Hogmark S.: Mechanical and tribological properties of multilayered PVD TiN/NbN coatings. Surface and Coatings Technology, 91, 43-49 (1997). https://doi.org/10.1016/S0257-8972(96)03118-0

[27] Shih K. K., Dove D. B.: Ti/Ti N Hf/Hf-N and W/W-N multilayer films with high mechanical hardness. Applied Physics Letters, 61, 654-656 (1992). https://doi.org/10.1063/1.107812

[28] Zeng Z., Zhou H., Long X., Guo E., Wang X.: Electrodeposition of hierarchical manganese oxide on metal nanoparticles decorated nanoporous gold with enhanced supercapacitor performance. Journal of Alloys and Compounds, 632, 376-385 (2015).

https://doi.org/10.1016/j.jallcom.2015.01.240

[29] Delezuk J. A. M., Pavinatto A., Moraes M. L., Shimizu F. M., Rodrigues V. C., Campana-Filho S. P., Ribeiro S. J. L., Oliveira O. N.: Silk fibroin organization induced by chitosan in layer-by-layer films: Application as a matrix in a biosensor. Carbohydrate Polymers, 155, 146151 (2017).

https://doi.org/10.1016/j.carbpol.2016.08.060

[30] Hoshi T., Saiki H., Anzai J-I.: Preparation of spatially ordered multilayer thin films of antibody and their binding properties. Biosensors and Bioelectronics, 15, 623 628 (2000).

https://doi.org/10.1016/S0956-5663(00)00113-5

[31] Huang Z., Cheng L., Sun Q., Liu B., Dong S.: Fabrication and electrochemical behaviors of multilayers composed of heteropholyanions and poly(diallyldimethylammonium chloride) on 4-aminothiophenol modified gold electrodes. Chinese Journal of Analytical Chemistry, 28, 1331-1335 (2000).
[32] Jin W., Bier F., Wollenberger U., Scheller F.: Construction and characterization of a multi-layer enzyme electrode: Covalent binding of quinoprotein glucose dehydrogenase onto gold electrodes. Biosensors and Bioelectronics, 10, 823-829 (1995).

https://doi.org/10.1016/0956-5663(95)99221-6

[33] Jeon J-W., Kwon S. R., Lutkenhaus J.: Polyaniline nanofiber/electrochemically reduced graphene oxide layerby-layer electrodes for electrochemical energy storage. Journal of Materials Chemistry A, 3, 3757-3767 (2015). https://doi.org/10.1039/c4ta04697h

[34] Wang X., Ma Y., Zhao M., Zhou M., Xiao Y., Sun Z., Tong L.: Determination of glucose in human stomach cancer cell extracts and single cells by capillary electrophoresis with a micro-biosensor. Journal of Chromatography A, 1469, 128-134 (2016). https://doi.org/10.1016/j.chroma.2016.09.054

[35] Barsan M. M., Ghica M. E., Brett C. M. A.: Electrochemical sensors and biosensors based on redox polymer/carbon nanotube modified electrodes: A review. Analytica Chimica Acta, 881, 1-23 (2015).

https://doi.org/10.1016/j.aca.2015.02.059

[36] Dagli U., Guler Z., Sarac A. S.: Covalent immobilization of tyrosinase on electrospun polyacrylonitrile/polyurethane/poly( $m$-anthranilic acid) nanofibers: An electrochemical impedance study. Polymer-Plastics Technology and Engineering, 54, 1494-1504 (2015). https://doi.org/10.1080/03602559.2015.1010218

[37] Yu L., Wei X., Fang C., Tu Y.: A disposable biosensor for noninvasive diabetic diagnosis rest on the $\mathrm{Au} / \mathrm{TiO}_{2}$ nanocomposite intensified electrochemiluminescence. Electrochimica Acta, 211, 27-35 (2016). https://doi.org/10.1016/j.electacta.2016.06.034

[38] Rawal R., Chawla S., Malik P., Pundir C. S.: An amperometric biosensor based on laccase immobilized onto $\mathrm{MnO}_{2} \mathrm{NPs} / \mathrm{cMWCNT} / \mathrm{PANI}$ modified Au electrode. International Journal of Biological Macromolecules, 51, 175-181 (2012). https://doi.org/10.1016/j.ijbiomac.2011.11.022

[39] Li S-J., Xia N., Lv X-L., Zhao M. M., Yuan B-Q., Pang H.: A facile one-step electrochemical synthesis of graphene/ $\mathrm{NiO}$ nanocomposites as efficient electrocatalyst for glucose and methanol. Sensors and Actuators B: Chemical, 190, 809-817 (2014). https://doi.org/10.1016/j.snb.2013.09.047

[40] Du J., Yu X., Di J.: Synthesis of Au-ZnS hybrid nanostructures and their application for electrochemical biosensor. Journal of Solid State Electrochemistry, 17, 109114 (2013). https://doi.org/10.1007/s10008-012-1862-9

[41] Palomar-Pardavé M., Scharifker B. R., Arce E. M., Romero-Romo M.: Nucleation and diffusion-controlled growth of electroactive centers: Reduction of protons during cobalt electrodeposition. Electrochimica Acta, 50, 4736-4745 (2005). https://doi.org/10.1016/j.electacta.2005.03.004 
[42] Sheridan E., Hjelm J., Forster R. J.: Electrodeposition of gold nanoparticles on fluorine-doped tin oxide: Control of particle density and size distribution. Journal of Electroanalytical Chemistry, 608, 1-7 (2007).

https://doi.org/10.1016/j.jelechem.2006.11.015

[43] Praig V. G., Piret G., Manesse M., Castel X., Boukherroub R., Szunerits S.: Seed-mediated electrochemical growth of gold nanostructures on indium tin oxide thin films. Electrochimica Acta, 53, 7838-7844 (2008). https://doi.org/10.1016/j.electacta.2008.05.069

[44] Bai Y., Bai Y., Wang C., Gao J., Ma W.: Fabrication and characterization of gold nanoparticle-loaded $\mathrm{TiO}_{2}$ nanotube arrays for medical implants. Journal of Materials Science: Materials in Medicine, 27, 31/1-31/11 (2016). https://doi.org/10.1007/s10856-015-5646-5

[45] Stoychev D., Papoutsis A., Kelaidopoulou A., Kokkinidis G., Milchev A.: Electrodeposition of platinum on metallic and nonmetallic substrates - Selection of experimental conditions. Materials Chemistry and Physics, 72, 360-365 (2001). https://doi.org/10.1016/S0254-0584(01)00337-6

[46] Sonavane A. C., Inamdar A. I., Shinde P. S., Desmukh H. P., Patil R. S., Patil P. S.: Efficient electrochromic nickel oxide thin films by electrodeposition. Journal of Alloys and Compounds, 489, 667-673 (2010).

https://doi.org/10.1016/j.jallcom.2009.09.146

[47] Karazehir T., Ates M., Sarac A. S.: Mott-Schottky and morphologic analysis of poly(pyrrole-n-propionic acid) in various electrolyte systems. International Journal of Electrochemical Science, 10, 6146-6163 (2015).

[48] Rassaei L., Sillanpää M., French R. W., Compton R. G., Marken F.: Arsenite determination in phosphate media at electroaggregated gold nanoparticle deposits. Electroanalysis, 20, 1286-1292 (2008).

https://doi.org/10.1002/elan.200804226

[49] Tyagi M., Tomar M., Gupta V.: NiO nanoparticle-based urea biosensor. Biosensors and Bioelectronics, 41, 110 115 (2013).

https://doi.org/10.1016/j.bios.2012.07.062

[50] Mohammadi A., Moghaddam A. B., Badraghi J.: Direct electron transfer of ferritin on electrodeposited nickel oxide cubic nanoparticles. Analytical Methods, 4, 1024 1028 (2012).

https://doi.org/10.1039/c2ay05596a

[51] El-rouby M., Aliyev A. S.: Electrical, electrochemical and photo-electrochemical studies on the electrodeposited n-type semiconductor hexagonal crystalline CdS thin film on nickel substrate. Journal of Materials Science: Materials in Electronics, 25, 5618-5629 (2014). https://doi.org/10.1007/s10854-014-2351-y

[52] Rammelt U., Bischoff S., El-Dessouki M., Schulze R., Plieth W., Dunsch L.: Semiconducting properties of polypyrrole films in aqueous solution. Solid State Electrochemistry, 3, 406-411 (1999).

https://doi.org/10.1007/s100080050174
[53] Thimsen E., Martinson A. B. F., Elam J. W., Pellin M. $\mathrm{J} .:$ Energy levels, electronic properties, and rectification in ultrathin $\mathrm{p}-\mathrm{NiO}$ films synthesized by atomic layer deposition. Journal of Physical Chemistry C, 116, 16830 16840 (2012).

https://doi.org/10.1021/jp302008k

[54] Pirvu C., Manole C. C., Stoian A. B., Demetrescu I.: Understanding of electrochemical and structural changes of polypyrrole/polyethylene glycol composite films in aqueous solution. Electrochimica Acta, 56, 9893-9903 (2011).

https://doi.org/10.1016/j.electacta.2011.08.061

[55] Chan X-H., Jennings J. R., Hossain A., Yu K. K. Z., Wang O.: Characteristics of p-NiO thin films prepared by spray pyrolysis and their application in CdS-sensitized photocathodes. Journal of The Electrochemical Society, 158, H733-H740 (2011). https://doi.org/10.1149/1.3590742

[56] Jana S. K., Majumder T., Banerjee S.: Enhanced photoelectrochemical property of gold nanoparticle sensitized $\mathrm{TiO}_{2}$ nanotube: A crucial investigation at electrode-electrolyte interface. Journal of Electroanalytical Chemistry, 727, 99-103 (2014). https://doi.org/10.1016/j.jelechem.2014.05.030

[57] Xia X. H., Tu J. P., Zhang J., Wang X. L., Zhang W. K., Huang H.: Electrochromic properties of porous $\mathrm{NiO}$ thin films prepared by a chemical bath deposition. Solar Energy Materials and Solar Cells, 92, 628-633 (2008). https://doi.org/10.1016/j.solmat.2008.01.009

[58] Meybodi S. M., Hosseini S. A., Razaee M., Sadrnezhaad S. K., Mohammadyani D.: Synthesis of wide band gap nanocrystalline $\mathrm{NiO}$ powder via a sonochemical method. Ultrasonics Sonochemistry, 19, 841-845 (2012). https://doi.org/10.1016/j.ultsonch.2011.11.017

[59] Babu G. A., Ravi G., Hayakawa Y.: Microwave synthesis and effect of CTAB on ferromagnetic properties of $\mathrm{NiO}, \mathrm{Co}_{3} \mathrm{O}_{4}$ and $\mathrm{NiCo}_{2} \mathrm{O}_{4}$ nanostructures. Applied Physics A, 119, 219-232 (2015). https://doi.org/10.1007/s00339-014-8951-9

[60] Liu P., Wang X., Li H.: Preparation of carboxylated carbon nanotubes/polypyrrole composite hollow microspheres via chemical oxidative interfacial polymerization and their electrochemical performance. Synthetic Metals, 181, 72-78 (2013). https://doi.org/10.1016/j.synthmet.2013.08.010

[61] Yu K., Kumar N., Roine J., Pesonen M., Ivaska A.: Synthesis and characterization of polypyrrole/H-beta zeolite nanocomposites. RSC Advances, 4, 33120-33126 (2014). https://doi.org/10.1039/c4ra03864a

[62] Chen W., Li X., Xue G., Wang Z., Zou W.: Magnetic and conducting particles: Preparation of polypyrrole layer on $\mathrm{Fe}_{3} \mathrm{O}_{4}$ nanospheres. Applied Surface Science, 218, 215-221 (2003). https://doi.org/10.1016/S0169-4332(03)00590-7 
[63] Sarac A. S., Ates M., Parlak E. A., Turcu E. F.: Characterization of micrometer-sized thin films of electrocoated carbazole with p-tolylsulfonyl pyrrole on carbon fiber microelectrodes. Journal of the Electrochemical Society, 154, D283-D291 (2007). https://doi.org/10.1149/1.2712134

[64] Kumar V., Misra N., Paul J., Dhanawade B. R., Varshney L.: Uricase-immobilization on radiation grafted polymer support for detection of uric acid using Agnanoparticle based optical biosensor. Polymer, 55, 2652 2660 (2014).

https://doi.org/10.1016/j.polymer.2014.04.012

[65] Kohma T., Hasegawa H., Oyamatsu D., Kuwabata S.: Utilization of AC impedance measurements for electrochemical glucose sensing using glucose oxidase to improve detection selectivity. Bulletin of The Chemical Society of Japan, 80, 158-165 (2007).

https://doi.org/10.1246/bcsj.80.158

[66] Hayat A., Barthelmebs L., Marty J-L.: Electrochemical impedimetric immunosensor for the detection of okadaic acid in mussel sample. Sensors and Actuators B: Chemical, 171, 810-815 (2012).

https://doi.org/10.1016/j.snb.2012.05.075

[67] Park J-Y., Chang B-Y., Nam H., Park S-M.: Selective electrochemical sensing of glycated hemoglobin (HbA1c) on thiophene-3-boronic acid self-assembled monolayer covered gold electrodes. Analytical Chemistry, 80, 80358044 (2008).

https://doi.org/10.1021/ac8010439

[68] Dominguez-Benetton X., Sevda S., Vanbroekhoven K., Pant D.: The accurate use of impedance analysis for the study of microbial electrochemical systems. Chemical Society Reviews, 41, 7228-7246 (2012).

https://doi.org/10.1039/c2cs35026b

[69] Mishra S. K., Srivastava A. K., Kumar D., Mulchandani A., Rajesh: Protein functionalized Pt nanoparticles-conducting polymer nanocomposite film: Characterization and immunosensor application. Polymer, 55, 4003 4011 (2014). https://doi.org/10.1016/j.polymer.2014.05.061

[70] Guler Z., Sarac A. S.: Electrochemical impedance and spectroscopy study of the EDC/NHS activation of the carboxyl groups on poly( $\varepsilon$-caprolactone)/poly(m-anthranilic acid) nanofibers. Express Polymer Letters, 10, 96-110 (2016).

https://doi.org/10.3144/expresspolymlett.2016.11

[71] Zehani N., Dzyadevych S. V., Kherrat R., Jaffrezic-Renault N. F.: Sensitive impedimetric biosensor for direct detection of diazinon based on lipases. Frontiers in Chemistry, 2, 44/1-44/7 (2014).

https://doi.org/10.3389/fchem.2014.00044
[72] Park J-Y., Park S-M.: DNA hybridization sensors based on electrochemical impedance spectroscopy as a detection tool. Sensors, 9, 9513-9532 (2009).

https://doi.org/10.3390/s91209513

[73] Ramya R., Sangaranarayanan M. V.: Polypyrrole microfibres synthesized with Quillaja Saponin for sensing of catechol. Sensors and Actuators B: Chemical, 173, 40-51 (2012).

https://doi.org/10.1016/j.snb.2012.05.034

[74] Tembe S., Kubal B. S., Karve M., D’Souza S. F.: Glutaraldehyde activated eggshell membrane for immobilization of tyrosinase from Amorphophallus companulatus: Application in construction of electrochemical biosensor for dopamine. Analytica Chimica Acta, 612, 212-217 (2008).

https://doi.org/10.1016/j.aca.2008.02.031

[75] Lupu S., Lete C., del Campo F. J.: Dopamine electroanalysis using electrochemical biosensors prepared by a sinusoidal voltages method. Electroanalysis, 27, 16491659 (2015). https://doi.org/10.1002/elan.201400680

[76] Lupu S., Lete C., Balaure P. C., del Campo F. J., Muñoz F. X., Lakard B., Hihn J-Y.: In situ electrodeposition of biocomposite materials by sinusoidal voltages on microelectrodes array for tyrosinase based amperometric biosensor development. Sensors and Actuators B: Chemical, 181, 136-143 (2013) https://doi.org/10.1016/j.snb.2013.01.060

[77] Pérez J. P., López M. S-P., López-Cabarcos E., LópezRuiz B.: Amperometric tyrosinase biosensor based on polyacrylamide microgels. Biosensors and Bioelectronics, 22, 429-439 (2006).

https://doi.org/10.1016/j.bios.2006.05.015

[78] Roychoudhury A., Basu S., Jha S. K.: Dopamine biosensor based on surface functionalized nanostructured nickel oxide platform. Biosensors and Bioelectronics, 84, 72-81 (2016). https://doi.org/10.1016/j.bios.2015.11.061

[79] Lete C., Lupu S., Lakard B., Hihn J-Y., del Campo F. J.: Multi-analyte determination of dopamine and catechol at single-walled carbon nanotubes - Conducting polymer - Tyrosinase based electrochemical biosensors. Journal of Electroanalytical Chemistry, 744, 53-61 (2015). https://doi.org/10.1016/j.jelechem.2015.03.005

[80] Min K., Yoo Y. J.: Amperometric detection of dopamine based on tyrosinase-SWNTs-Ppy composite electrode. Talanta, 80, 1007-1011 (2009). https://doi.org/10.1016/j.talanta.2009.08.032 